\title{
WestVirginiaUniversity
}

THE RESEARCH REPOSITORY @ WVU

Graduate Theses, Dissertations, and Problem Reports

2008

\section{Leadership and organizational culture transformation in professional sport}

Joe Frontiera

West Virginia University

Follow this and additional works at: https://researchrepository.wvu.edu/etd

\section{Recommended Citation}

Frontiera, Joe, "Leadership and organizational culture transformation in professional sport" (2008).

Graduate Theses, Dissertations, and Problem Reports. 4374.

https://researchrepository.wvu.edu/etd/4374

This Dissertation is protected by copyright and/or related rights. It has been brought to you by the The Research Repository @ WVU with permission from the rights-holder(s). You are free to use this Dissertation in any way that is permitted by the copyright and related rights legislation that applies to your use. For other uses you must obtain permission from the rights-holder(s) directly, unless additional rights are indicated by a Creative Commons license in the record and/ or on the work itself. This Dissertation has been accepted for inclusion in WVU Graduate Theses, Dissertations, and Problem Reports collection by an authorized administrator of The Research Repository @ WVU.

For more information, please contact researchrepository@mail.wvu.edu. 
Leadership and Organizational Culture Transformation in Professional Sport

Joe Frontiera, MS

Dissertation submitted to the College of Physical Activity and Sport Sciences

at West Virginia University

in partial fulfillment of the requirements for the degree of

\author{
Doctor of Philosophy \\ in \\ Kinesiology \\ Jack C. Watson, Ph.D., Chair. \\ Ed Jacobs, Ph.D. \\ Vanessa Shannon, Ph.D. \\ Jaci Webb-Dempsey, Ph.D \\ Sam Zizzi, Ed.D
}

Morgantown, West Virginia

2008

Keywords: Organizational culture, culture change, leadership, performance 


\section{ABSTRACT \\ Leadership and Organizational Culture Transformation in Professional Sport}

Joe Frontiera, M.S.

Schein (1992) defined organizational culture as "a pattern of shared basic assumptions that the group learned as it solved its problems of external adaptation and internal integration” (p. 12), and organizational culture has long been recognized as a moderator to performance in business (Baalthazard, Cooke, \& Potter, 2006; Kotter \& Heskett, 1992; Smerek \& Denison, 2007). The purpose of this qualitative study was to examine the phenomena of organizational culture change in professional sport (National Basketball Association, Major League Baseball, and National Football League). Of the 32 teams that met criteria for inclusion, six agreed to participate. Specifically, leaders (owners or general managers) who had successfully brought their organizations through organizational culture change, as evidenced by their team's performance, agreed to an in-person interview. Modified interpretive analysis was utilized to analyze the data (Hatch, 2002), from which five primary themes emerged (Symptoms of a Dysfunctional Culture, My Way, Walk the Talk, Embedding New Culture, and Our Way). These themes and their respective subthemes were highly inter-related and together formed an initial model for organizational culture change in professional sport: the Culture Change Cycle. Each theme along with the overall model is discussed in depth, and differences across sport and role are explained. 


\section{TABLE OF CONTENTS}

Page \#

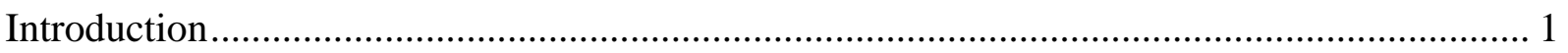

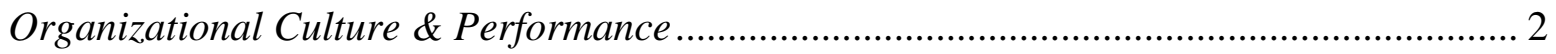

Culture Formation: A Leader's Impact ................................................................ 7

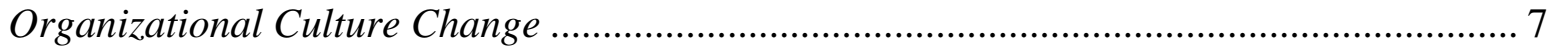

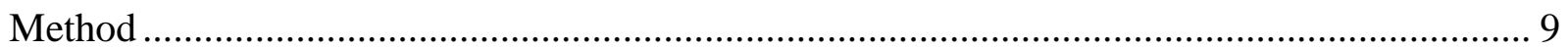

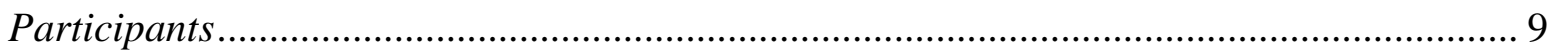

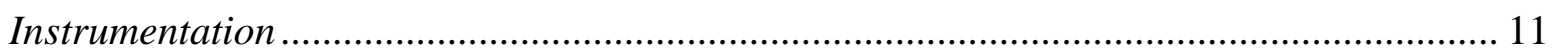

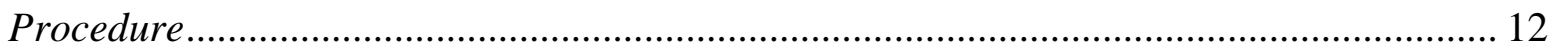

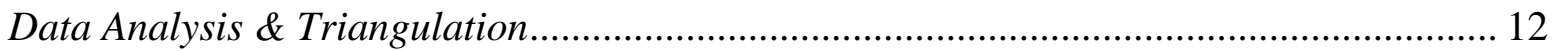

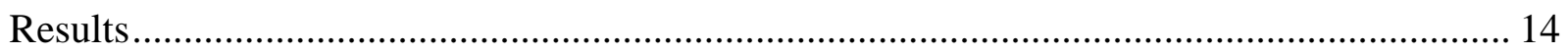

Symptoms of a Dysfunctional Culture ........................................................................... 14

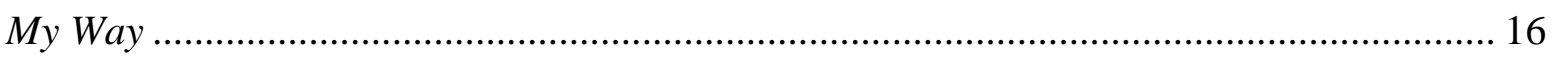

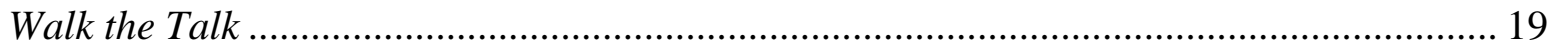

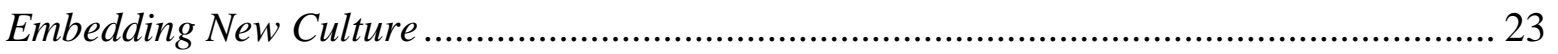

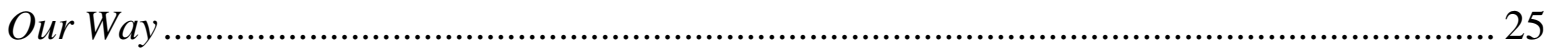

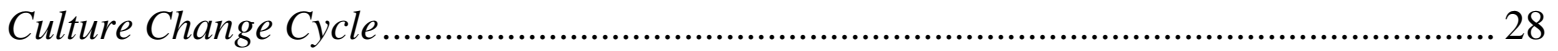

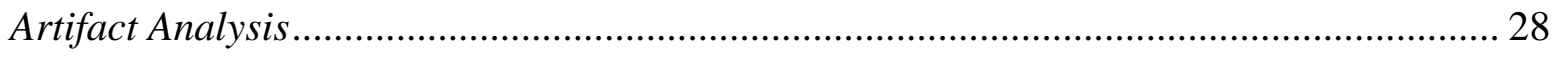

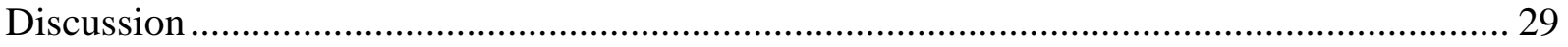

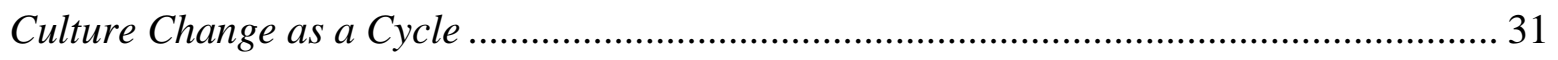

Differences Across Roles ........................................................................................ 33

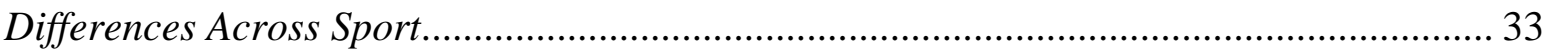




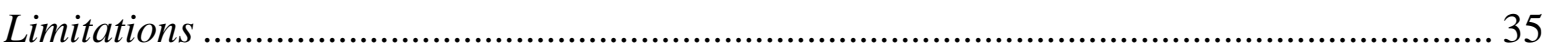

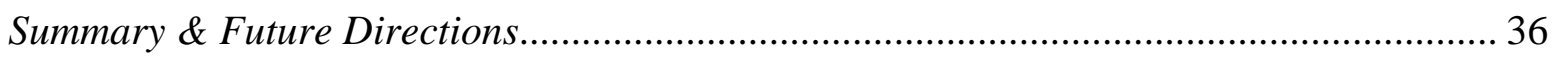

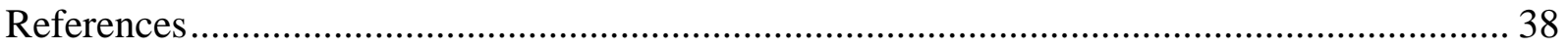

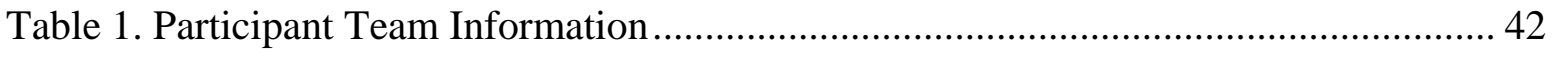

Table 2. Reflection of Schein’s (1983) Five Principles in Interview Protocol ...................... 45

Figure 1. Culture Change Cycle.......................................................46

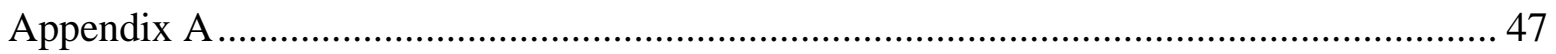

Brief Participant Biography .......................................................................................... 47

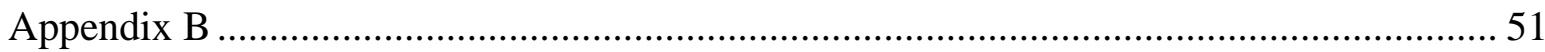

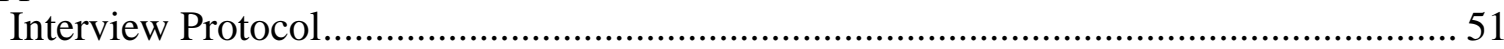

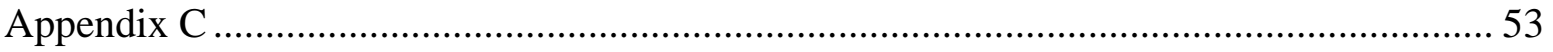

Cover Letter to Participants ............................................................................................... 53

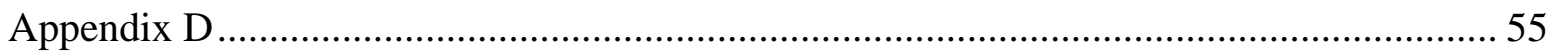

Simple Artifact Checklist......................................................................................... 55

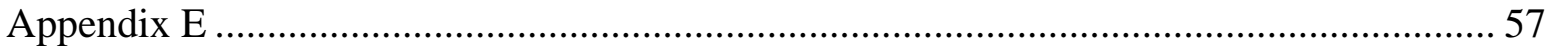

Researcher's Bias of Organizational Culture............................................................... 57

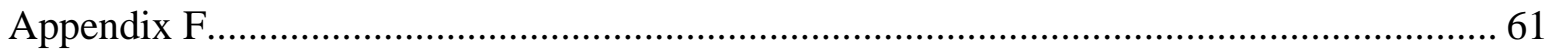

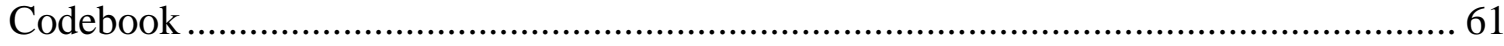

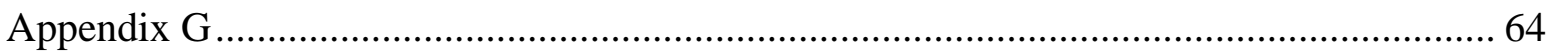

Artifact Frequency Analysis ....................................................................................... 64

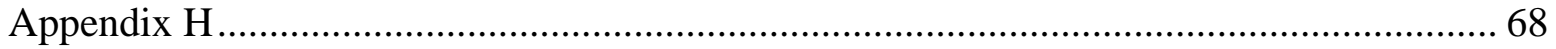

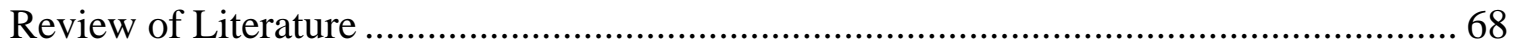




\section{LIST OF TABLES}

Page

Table 1 - Participant Team Information...............................................42

Table 2 - $\quad$ Reflection of Schein's (1983) Five Principles in Interview Protocol..............45 


\section{LIST OF FIGURES}

Page

Figure 1. Culture Change Cycle...............................................46 


\section{Introduction}

Williams and Straub (2001) suggest that sport psychology developed largely from the fields of physical education and exercise science. However, Coleman Griffith, widely considered the "grandfather” of North American sport psychology, was a psychologist by training (Zaichkowsky \& Naylor, 2005). Other pioneers in the field, such as Bruce Ogilve and Tom Tutko, were also trained psychologists. Through these individuals and others like them, sport psychology has borrowed significant theory from social and industrial-organizational psychology on a variety of subjects ranging from personality to group dynamics and leadership.

More specifically, applied sport psychology is defined as "identifying and understanding psychological theories and techniques that can be applied to sport and exercise to enhance the performance and personal growth of athletes” (p. 1; Williams \& Straub, 2001). With such a broad definition, it is surprising that practitioners in the field beleaguer the fact that there is a limited market for sport psychology services, and that so few sport and exercise psychology professionals can make a living consulting on a full time basis (Meyers, Coleman, Whelan, \& Mehlenbeck, 2001). Most professionals in the field have taken a physiological or cognitivebehavioral approach to the application of their discipline, and focus primarily on working directly with individual athletes, teams and coaches. However, more recently, the field of “performance psychology”, a hybrid of sport psychology, organizational consulting, and performing arts psychology, has emerged (Hays, 2006). The term typically refers to the psychology of excellent performance. Performance psychology has the potential for a more widespread application both within the realm of sport and in other disciplines in which high "performance" is required. 
In further exploring performance psychology's application, it would be appropriate to examine the possibilities for performance enhancement in sport organizations outside of the context of developing specific mental skills. There are many avenues to pursue this goal, some of which lead back to the roots of traditional sport psychology and integration of industrialorganizational psychology concepts. Specifically, organizational culture has long been recognized as a moderator to performance in business (Baalthazard, Cooke, \& Potter, 2006; Kotter \& Heskett, 1992; Smerek \& Denison, 2007) and warrants further exploration as a possible lever for performance improvement in professional sport organizations. To better comprehend this potential impact it is necessary to understand both of the archetypal definitions of organizational culture as well as the multiple approaches to cultural research.

\section{Organizational Culture \& Performance}

Organizational culture, in laymen's terms, is often described as "the way we do things around here" or the values that hold an organization together, yet academic researchers have struggled to find consensus on a precise definition of culture. Ideational definitions emphasize cognitive aspects of culture, such as 'meanings' and 'understandings' (Martin, 2002). For example, Louis (1985) defined culture as a set of “meanings shared by a group of people” (p. 74). Researchers relying on an ideational approach, for example, would examine the meaning organizational members attribute to common myths or stories within the organization. Other definitions of culture are primarily materialistic, and focus on the material manifestation of ideations. Mills (1988) suggested that culture is the "manifestations of a process of ideational development located within a context of definite material conditions” (p. 366). A researcher relying on the materialistic approach would examine dress, workplace environment, hierarchy, 
and job descriptions. Subjectively, the researcher must determine what each materialistic item means.

Along with multiple approaches to defining culture, there are diverse methods to approaching cultural research: integration, differentiation, and fragmentation (Meyerson \& Martin, 1987). Studies from the integration perspective assume that all members in an organization share one consensus of culture, and there is clarity surrounding this consensus. In contrast, research grounded in the differentiation approach suggests that elements of culture can be inconsistent. Although consensus of meaning may exist with smaller subgroups of an organization, agreement may not exist across subgroups or throughout the entire organization. Furthermore, there may be ambiguities within the smaller groups, as evidenced by leaders who say one thing and do the exact opposite. Finally, the fragmentation approach takes differentiation one step further to suggest that ambiguity is the 'essence' of organizational culture. Consensus depends wholly upon the issue in question and can never exist across an organization (Martin, 1992).

Schein (1992) provides a definition of organizational culture that integrates both the ideational and materialist components of culture and is general enough in its wording to allow for elements of differentiation:

A pattern of shared basic assumptions that the group learned as it solved its problems of external adaptation and internal integration, that has worked well enough to be considered valid and, therefore, to be taught to new members as the correct way to perceive, think, and feel in relation to these problems. (p. 12) Schein $(1990,1992)$ goes on to define the three levels of organizational culture: artifacts, values and underlying assumptions. The first, or outer, level is composed of the artifacts that an 
organization makes public: for example, a vision statement, company slogan, statues, or even the way cubicles are arranged can provide indications of the deeper levels of a culture. Values, the second level of culture, are reflected in how members interact with one another, how members interact with their environment, and what constructs, such as honesty, integrity or profitability, members share (Schein, 1992). The third and deepest level of organizational culture consists of the underlying assumptions. In healthy organizations, these assumptions provide the basis for the values. For example, if integrity is valued, the underlying assumption may be that only honesty can lead to success.

After defining organizational culture and its tenets, researchers began to examine the relationship between organizational culture and performance. Kotter and Heskett (1992) have made a compelling case that culture does impact performance. More specifically, these authors outline three general types of culture (strong, strategically appropriate, and adaptive) and the way each of these cultures impact performance. A strong culture is one in which the organization has an evident, notable style. A strategically appropriate culture is one that appropriately fits within its current internal and external environment. Finally, an adaptive culture is one that assists members anticipate and adapt to environmental change.

Over the span of four years, Kotter and Heskett (1992) investigated the impact each of these three types of organizational culture can have on performance by analyzing performance metrics for hundreds of organizations. Specifically, they identified which of the three culture types was present in each organization and examined the relationships between each specific culture type and successful outcomes. They found that there was a general positive correlation between strength of corporate culture and market value $(r=.26)$, net income growth $(r=.46)$, and return on average investment $(\mathrm{r}=.31)$; however, these correlations were relatively weak and 
lacked consistency. After matching high performance organizations with low performance organizations and interviewing members, Kotter and Heskett (1992) found those individuals in companies with lower performance felt that their company's culture hurt their performance and did not fit their industry, while those individuals in higher performing organizations felt their culture helped their performance and was a good fit for their industry.

Kotter and Heskett (1992) found that the best performing organizations were those with an adaptive culture, where the culture encourages continuous adaptation and values change. This change-embracing culture must come from leadership, and while the adaptive culture must value leadership, the leadership, reciprocally, must value the core constituencies of the organization (e.g., customers, stockholders and employees; Kotter, 1990). As a result, Kotter and Heskett (1992) posed the question "how much does the culture value excellent leadership from its managers?” They found that individuals within higher-performing firms placed a significantly higher value on excellent leadership than those individuals within lower performing firms. Furthermore, those in higher performing firms valued their customers $\left(\mathrm{M}_{\text {higher }}=6.0 ; \mathrm{M}_{\text {lower }}=\right.$ 4.6), employees ( $\left.\mathrm{M}_{\text {higher }}=5.8 ; \mathrm{M}_{\text {lower }}=4.1\right)$ and stockholders $\left(\mathrm{M}_{\text {higher }}=5.7 ; \mathrm{M}_{\text {lower }}=3.9\right)$ significantly more than those in lower performing firms.

Previous research seems to suggest a relationship between the types of organizational culture and performance (Kotter \& Heskett, 1992). More recent research has investigated other mediators of the relationship between an organization's culture and its performance. Specifically, Balthazard, Cooke and Potter (2006) suggested that behavioral norms within an organization are reflective of that organization's culture, or its values and assumptions, and may have a heavy impact on an organizations performance. The authors surveyed over 60,000 participants using the Organizational Culture Inventory (OCI), an instrument that assesses twelve different 
behavioral norms that, either consciously or unconsciously, may be required for members to fit in and meet an organization's expectations (Cooke \& Lafferty, 1989). Balthazard and colleagues (2006) found that each of the four behavioral norms classified as “constructive” was positively correlated with role clarity, communication quality, "fit" with organization, and job satisfaction, and negatively correlated with behavioral conformity. Furthermore, these constructive norms were also positively correlated with performance drivers, such as quality of products/services, quality of customer service, adaptability, and quality of workplace, while negatively correlated with turnover.

More recently, Smerek and Denison (2007) used archived data measuring four components of organizational culture - involvement, consistency, adaptability and mission from 102 publicly traded companies. The researchers found that both adaptability and involvement were positively correlated with return on assets, and that this relationship was strongest in the third year after the culture measures were taken. This indicates that these two cultural elements may have their greatest impact on performance in the future. Furthermore, all four of these cultural elements were positively correlated with short-term sales growth, suggesting that short-term performance may be predicted by these elements.

In summary, similar to Kotter and Heskett (1992), Balthazard and colleagues (2006) found that organizations that focus outwardly on customers and stockholders and internally on employee fit and communication have stronger performance. They also provided compelling evidence that members' behavioral norms, indicative of the culture, were related to the organization's performance. In addition, Smerek and Denison (2007) found that two elements of culture - involvement and adaptability - had a strong correlation to return on assets in the future and relate strongly to short term sales growth. Although each of the above studies is correlational 
in nature, the results of these studies consistently suggest a relationship has emerged between those cultures that are adaptive and organizations that have consistently high performance. Assuming this link between culture and strong performance exists, the concept and process of culture formation takes on increased significance as culture formation may impact future organizational success.

\section{Culture Formation: A Leader's Impact}

Schein (1985) states that the “...only thing of real importance that leaders do is create and manage culture" (p.2) and that a culture takes shape from both the assumptions and theories of the founder as well as the organization's collective lessons from its own unique experience (Schein, 1983). According to Schein (1983), five principles form the structure of any culture: relationship to the environment; the nature of truth; the qualities of human nature; the nature of human activity; and the nature of human relationships. Leaders typically model these principles, both through what they focus on and how they react to critical events. Specifically, Schein (1983) suggested that culture is created through the observance of the set of behaviors demonstrated by leaders that immediately follow a critical incident and the evaluation of whether those behaviors are effective.

In an effort to determine whether leadership primarily influences culture or culture influences leadership, Sarros, Gray and Densten (2002) found that certain elements of leadership impacted culture far more than culture impacted leaders. For example, a transactional leadership style, which assumes that the leader-follower relationship is a process of reward (success) and punishment (failure), accounted for $24 \%$ of the variance of the cultural aspect of emphasis on rewards.

Organizational Culture Change 
In addition to driving cultural formation, leaders can also foster cultural change. Before understanding the way in which leaders serve as facilitators, it is important to first understand the nature of organizational culture change. Organizations find numerous reasons to change their culture, from increasing collaboration, initiative, and accountability (Kanter, 2004) to adapting to external change (Singh, 2006). Inherent in each of these culture change rationalizations is the basic desire to improve performance. Schein (1990) asserts that three steps need to occur in order to successfully change culture. First, leaders need to "unfreeze” the present system by outlining and discussing impending threats to the organization if no change occurs. Second, a new direction needs to be formalized along with a new set of assumptions; this step is the actual "change”. Finally, members of the organization need to be positively reinforced when their actions align with the new assumptions, and punished when they adhere to old assumptions. This third step is "refreezing" the new culture.

This three-step process is seemingly simple, yet culture is difficult to change. Smith (2003) reported that in a group of North American corporations that had attempted culture change, only $19 \%$ of managers rated the culture change as 'extremely successful'. Kotter and Haskett (1992) claim that culture is difficult to change due to the interdependence between and within the levels of culture, such as values and underlying assumptions.

In order to successfully alter culture, leaders must address a situation that has previously been ignored, increase collaboration, and inspire initiative (Kanter, 2004). To emphasize this point, Kanter provides one of the only examples in the literature of organizational culture change pertaining to professional sport: the turnaround of the Philadelphia Eagles. Since Jeffrey Lurie purchased the organization in 1994, the Eagles have embarked on a remarkable turnaround. 
Although they have yet to win a championship, the Eagles have been one of the most successful organizations in the NFL in the past ten years.

Although there has been significant research into the construct of organizational culture and change within business, this phenomenon has not been examined within professional sport other than the above reference by Kanter (2004). Professional sport is simply a business with a unique product - a team. Due to the compelling relationship between a healthy organizational culture and strong performance, it is arguable that the lack of success of a professional sport team can be symptomatic of a larger problem within that organization's culture. Furthermore, new leadership is often required to make changes to an organization's culture. While this leads to many inquiries that have yet to be explored in the sport literature, this study was designed to concentrate on one primary question (1) and two secondary questions (2, 3):

1. In what manner do leaders create more of a performance-oriented culture in professional sport organizations?

2. Are leaders in professional sport consciously aware of the critical elements of the culture of their organization?

3. What similarities and differences exist in leaders' efforts to bring about culture change across organizations?

Method

\section{Participants}

Intensity sampling and operational construct sampling were utilized in selecting participants. Intensity sampling consists of selecting cases that are rich examples of the subject matter being studied (Patton, 2002). In this case, target participants were owners and/or general managers who have successfully brought about organizational culture change within their 
respective professional sport teams as evidenced by their team’s on-field or on-court performance. Operational construct sampling entails the utilization of real-world examples (Patton, 2002). Therefore, owners and/or general managers from the National Football League (NFL), National Basketball Association (NBA), and Major League Baseball (MLB) were interviewed.

To be selected as participants for this research, leaders had to meet four specific criteria. First, the leader had to be the decision maker within his or her organization. Because decisionmakers vary between organizations (i.e., owner, general manager), the primary investigator determined whether the owner, general manager, or both make the majority of organizational decisions. This was accomplished through organizational research, including in-depth analysis of articles about personnel changes within the organization. In cases where there was confusion, the primary investigator called the organization to ask who made most of the day to day decisions. In one case multiple leaders were identified as decision-makers, and the primary investigator selected one. The remaining three criteria are as follows:

1. In the NBA and NFL, the leader's respective team must have increased its winning percentage by $25 \%$ in consecutive years. Due to the high number of regular season games in MLB, the leader's team must have increased its winning percentage by a total of $10 \%$ in a two year period.

2. In addition to this increase in performance, the team must have maintained a record that is over .500 for three years after increasing its winning percentage. For example, even though the 1998 Boston Celtics increased their winning percentage by .256, they would not qualify as their overall record (36-46) was well below .500. This criterion prevents any team after 2004 from being included in this research. 
3. The leader's team must have had seasons with a winning percentage at or below .500 in at least two of the three seasons prior to the increase in performance.

The primary investigator identified all potential participants through the use of team, organizational and sport websites (i.e., www.sportsecyclopedia.com), each of which contained resources for professional sport teams including history, records, playoff appearances and other general information. The primary investigator then cross-referenced team records with historical personnel information to identify both owners and general managers that met the specified criteria.

Since 1995, there have been 32 organizations across the three sports that meet the criteria stated above ( $n=12$, MLB; $n=12$, NFL; $n=8$, NBA). Of these 32 cases, the primary investigator attempted to select a representative sample of both roles (general manager, owner) and sport type (basketball, football, baseball).

The final sample $(N=6)$ included two owners and one general manager from the NFL, two general managers from the NBA, and one general manager from Major League Baseball. Participants' team information is included in Table 1, and a brief biography of each participant can be found in Appendix A.

\section{Instrumentation}

The interview protocol was developed by the primary investigator and modified by an expert in qualitative research (Appendix B). The final interview elicits a description of participants' backgrounds, along with the recalled culture when the leader arrived, the leader's values, change processes, critical events that have required the leadership of the participant, and the vision of the participant. Interview questions were designed to align with Schein’s (1983) 
five principles that form the structure of organizational culture. These principles along with questions that align with each can be found in Table 2.

Procedure

Each participant was contacted via telephone or email. In most cases, the primary researcher had no direct contact with the executive prior to the meeting, as the meeting was arranged through an administrative assistant. A cover letter explaining the rights of research participants was emailed to participants once they agreed to an interview (Appendix C). In order to further inform the interview, web research was conducted on the participant and the organization. The primary investigator then traveled to each participant's work location to conduct the interview. Immediately prior to beginning the interview, the primary investigator again explained the purposes of the study and risks as per Institutional Review Board regulations.

Semi-structured, open-ended interviews were conducted with each participant. The protocol provided the framework for the interview, while the primary investigator asked various follow-up questions based on participants’ responses. All interviews were recorded for accuracy, using a digital voice recorder. The primary investigator also took detailed notes during the interview. Interviews averaged 59 minutes, ranging from 31 minutes to 76 minutes.

The primary investigator also obtained permission to view facilities in order to examine artifacts that offered further insight into the interview and an organization's culture. A simple artifact checklist was utilized to guide the primary investigator in his observations. (Appendix D).

Data Analysis \& Triangulation 
Upon completion of the interviews, each recording was digitally copied to protect the integrity of the data. Each interview was fully transcribed by the primary researcher and doublechecked for accuracy. A modified interpretive analysis was used to guide the inquiry into the data. The purpose of this type of analysis is for the researcher to "produce meaning that makes sense of the social phenomena” being studied (p. 180; Hatch, 2002). The primary investigator followed the general format outlined by Hatch (2002) in the interpretive analysis process, which includes reading the data for a sense of the whole, identifying impressions in the form of memos, and then coding the transcriptions where impressions are supported or challenged; however, along with the creation of memos during the first reading, open coding was also employed. The researcher also attempted to increase his own awareness of his biases and prejudices in order to reduce his influence to the overall process (Merriam \& Associates, 2002; see Appendix E).

In addition, data was analyzed both within case on multiple levels including leader, sport and roles and cross-case, or across leaders, sports and roles. Furthermore, multiple levels of coding were utilized. First, open coding, or identifying and tentatively naming potential categories of the phenomena, was used to initially examine the data. Second, through comparing and combining codes and examining memos, open codes were separated into general categories. Finally, relationships between categories emerged as the higher order themes. The resultant codebook is included as Appendix F.

This research incorporated multiple forms of triangulation. First, six separate collection points were utilized as each participant was asked the same set of questions. Second, data triangulation occurred through the use of both interview data and document/artifact analysis. Document/artifact analysis provided both context for interviews and ensured that participants' words are reinforced with the items and information an organization chooses to display. Third, 
investigator triangulation took place as a second researcher, who has extensive training in qualitative analysis, separately examined and coded the data to provide a source for inter-rater reliability. Disparities in the coding process between the primary investigator and the secondary researcher were discussed until a consensus was reached. Finally, participant triangulation was used as each participant was provided the opportunity to offer feedback on the conclusions of the primary investigator.

Results

To assess the first and second research questions, interpretive qualitative analysis was conducted. Five separate themes emerged, each of which had multiple subthemes. Emergent themes included symptoms of a dysfunctional culture, my way, walk the talk, embedding new culture, and our way. These themes have been organized into a schematic that outlines the process of culture change in professional sport organizations (see Figure 1), and will be discussed in-depth in the following section. Textual examples extracted from interview transcriptions will be provided along with an in-depth explanation of each theme and corresponding subtheme. In select cases, the primary investigator has included words or phrases within brackets that will assist with context. Symptoms of a Dysfunctional Culture

Five of six participants were aware of dysfunctional elements within the culture they had joined. In some instances, symptoms were tangible, such as sub-standard facilities or a win-loss record; in other instances they were abstract, relating to attitudes or values. Examples were wide ranging and have been organized into two subthemes: negative environment and a losing habit.

Negative environment. Five of the six participants were able to identify adverse elements of their respective organization’s environment, both physical and psychological. Physical elements 
included poor facilities, while psychological elements consisted of the absence of important values such as trust, honesty and integrity. Additionally, leaders identified values that were not perceived to be conducive to success, including selfishness, placing too much emphasis on monetary profit and minimizing the value of players. In two cases, new leaders discovered that bad leadership had been contributing to the negative environment.

The working environment was very poor, in the bowels of [our] stadium. Owner1, NFL

There had been some cultural issues with respect to where winning and where players stood in the pecking order...the focus had been before [owner] took over on maximizing revenues above all else. Not that that's not a good thing, but some of it was at the expense of facilities, some of it was at the expense of efficiencies, and some of it was at the expense of alienating players. - GM, NFL

Losing habit. In many ways, teams had become accustomed to mediocrity. Across all participants a losing habit had become the norm, bad decisions were common, and there was little confidence in the organization. Furthermore, a minimal level of accountability, effort and communication existed throughout the organization. All of these factors contributed to a low fan base.

The culture was kind of one where they accepted being mediocre, they accepted that they were a mid-market club, and you heard that a lot. And everyone accepted “we're a mid-market club; our revenues are about halfway through”. $-G M, M L B$ 
The team just had not been successful for a long time. What transpires when you aren't successful for a long time is you get a lot of bad attitudes, you get a lot of “well, here we go again” type things, because you just haven't had any success. And it was always the glass is half empty rather than half full. - GM 2, NBA My Way

Simultaneous to noting the dysfunctional elements of the culture, leaders soon let the organization know that there was a new way to do things. In all but two cases, this occurred immediately after they assumed their new position. In one case, the "new way” was delayed roughly one year so the new owner could get acclimated to sport ownership. In another case, the owner had been with the franchise for his entire adult life. The second major theme, My Way, was best articulated by GM 1 in the NFL when reflecting upon a key decision during his first days in his new position as President and General Manager:

I also thought it would send a message to everyone else in the building that this is a new era, with new people, and a new approach to things and, this is the way we're going to do it.

This theme was prominently expressed by all participants, and was comprised of five subthemes: vision, my values, change personnel, grow people, and explicit communication.

Vision. Vision was commonly expressed with the very simple sentiment of winning, or making the organization better. Additionally, this subtheme was often coupled with the planning process, or a blueprint for winning.

It's win. Take this club to the top, but do it the right way. Do it by having a good scouts, who sign good players, who will be passed on to good player 
development people, who would all understand [our] way of playing the game on the field. - GM, MLB

I hand wrote on a piece of paper five points. And I would read them and have them with me every night when I went to bed, and when I woke up in the morning. It was really more of how to become a very good football team. But with that is obviously a very good organization. Owner $1, N F L$

My values. Values were brought to the organization by the leader, and provided a foundation for future success and a basis for organizational decisions. Values were diverse, and include honesty, integrity, loyalty, trust, commitment, dignity, professionalism, philanthropy and team. Many values related specifically to the leader's belief in how people should treat one another. Values were often implicitly expressed through stories and anecdotes about past decisions.

I've always said that people have my trust and loyalty implicitly and will always have it until you prove to me that you don't deserve it. - GM 1, NBA I think that people understand that we have integrity and that's the prime part of the way we operate. We try not to lose our integrity because of some difficult decisions. - Owner 2, NFL

I really feel like if you can respect and validate the people around you then can get the best from them. - Owner 1, NFL

Change personnel. Five of the six participants explicitly stated that it was necessary to bring new people into the organization, individuals who shared their values and were familiar with their methods. When looking for new personnel, whether it was front-office, coaches, or players, four leaders expressed that they minimized experience and instead looked at a person's 
potential, or 'ceiling'. Considerable risk accompanied the decision to bring in a coach with no experience, for if the person failed at their task then it was likely that the leader would be blamed. Even with that knowledge, all six participants had hired a coach with no previous headcoaching experience. Additionally, the concept of hiring the "best people” consistently arose indicating that a potential employee, whether a player or coach, had to have credibility, work hard, be innovative, passionate and have a positive attitude.

Once things go wrong in a certain way so long, you know the only way to change that is to start changing the pieces of the group. - GM 1, NBA

That's one of the management mistakes or hiring mistakes that a lot of people make - that they put experience higher on the criteria level than they should. - GM, MLB A lot of it was having to hire key executives that would be the, I guess you'd call them, the lieutenants of change, the ones that would absolutely make it their highest priority to be part of the change of the culture and the attitude and of the whole direction. - Owner1, NFL

Grow people. All participants expressed interest in the growth of those who worked for them. This growth occurred with employees in their present jobs, when they advanced to new positions, and when they adopted a new mindset or philosophy. The growth mindset that each leader displayed demonstrated a long-term investment in individuals working for the organization and a sincere passion for development.

My philosophy has always been to try and help people do their jobs better. Because if players don't do well and coaches don't coach well, the team's not going to be successful, and then you're not going to be successful. - GM 1, NBA 
One of the great joys of coaching or being involved in this business is seeing the people you work with accept your philosophy and grow. - GM, NFL

Our vision is to bring in good people, and you just promote them, you train them, you promote them, and you keep them. - GM, MLB

Explicit communication. Simply having a compelling vision was not enough to promote change. It was critical for leaders to honestly and clearly communicate their vision, plan, and expectations to both players and staff. All six participants verbalized this sentiment. These communication efforts occurred either on a scheduled basis or in an ad hoc manner. Additionally, the coach was expected to act as a critical advocate and mouthpiece for communicating participants' expectations.

I meet with the marketing and sales staff and front office staff twice a year, once in the off season to explain what we're going to do in the off season, and once at the beginning of the season. - GM, NFL

You try to tell people what you expect and what you want to do and after that you leave them alone and let them do their job. - GM 1, NBA

I always try to talk to the players four or five times a year. I'll have a meeting where we talk about where we are, what we need to do. - GM 2, NBA Walk the Talk

The third major theme endorsed by all participants, Walk the Talk, alludes to the method used to implement the plan that allowed each organization to progress towards the vision of its leader. Stated simply, this is 'how' the organization found success. This occurred through a mixture of daily events and critical organizational decisions. 
You know, you say it and say it, but it's how you do it. You can say things and not really carry it out, you know what I mean? So we try to do it both ways. We try to say our goal is to win, and we're going to do whatever it takes, and then do it. Owner 2, NFL

Once again, this theme was often articulated through stories that reflected a passion for their jobs and an awareness of how their actions were scrutinized by those they were tasked to lead.

When I was GM here, I might get home at 11 at night, but at 8:15 I was here, why? Because the people here in this department, I wanted to show them, hey, I want them dedicated. It's not fair for me to stroll in at 10:00 but they have to be here at 8:30. No. But that's what you do, you lead by example. - GM, MLB The participants suggested that this sentiment was often reflected in the players that each leader pursued:

Even though he's [player] not a very talkative guy, he leads by what he does, he guards, he does all the little things you have to do to win.- GM 2, NBA Walk the Talk encompasses four subthemes, including day to day, obstacles to change, critical events, and artifact impact.

Day to day. Three leaders repetitively acted on a daily basis to communicate their message and perpetuate the plan. The manner in which the leader handled non-critical decisions was also important. Furthermore, it was crucial to maintain an attention to detail.

It's really everyday decisions, it's what you do, you try to do things right. - Owner 2, NFL

One of the keys to the success has definitely been an attention to detail. It's not like you say, here's a weight room, or here's a training table. What are you surrounding 
it with? Exactly what is the equipment? What is the rehab mechanism? Do we have everything you can have to get a human being to heal? And can we do better? -

Owner 1, NFL

Obstacles to change. The integrity of the leader's vision/plan must be upheld despite organizational barriers that had previously been used as excuses. It was important for executives to view these as challenges to be overcome rather than legitimate reasons for failure. Examples included a team's perceived small market status, lack of a fan base and a harsh economic environment. Some of the same physical symptoms of a negative culture identified in the negative environment subtheme, including dilapidated facilities or a lack of a practice facility, were acknowledged with the caveat that they were no longer a legitimate reason for poor performance.

Part of it is we had no practice facility before that. We were practicing in the Salvation Army. We practiced over at the [police station] for a couple years, where you had a two hour window of your day when you could practice. - GM 1, NBA What I tried to do was to, to change the culture to the degree that we are going to win, it has nothing to do with where we're located, we can sell tickets, we can be successful here. - GM 2, NBA

One critical component of obstacles to change was media and fan pressure. All participants explicitly stated that the media could be a powerful force and would attempt to derail the organization’s focus in a quest for the next big story. Both media and fans were sometimes critical of an organization's actions, or inaction, as each group craved the “quick fix”. It was necessary for leaders and organizational members to ignore this pressure an remain focused on the larger plan. 
There's gonna be a lot of public criticism, and there's gonna be a lot of back biting, and there's gonna be a lot of second-guessing, and you just have to ride that out. You know, you just have to stick your chin into the wind and ride it out. - GM, MLB If you really want to run a successful organization, a lot of the outside world wants a quick fix and will always go for the quick fix, however they perceive that to be.Owner 1, NFL

Critical events. Five of six participants relayed examples of important events that they presided over. Each was a value-driven decision that relayed to the organization that either new values existed or old behaviors would not be tolerated. Examples were wide-ranging, and included changes in the front office, on the field, and with the coaching staff.

The specific event that turned us around was trading Player 1 for Player 2. Player 1 was the face of that franchise, he was much younger than Player 2, at the time we did it it was a very controversial trade, because a lot of people felt, 'why are you trading this great young talent for an older guy with problems?'... [it communicated] that we weren't going to have selfish people. That we were gonna have people that were committed to the team, and it didn't matter who they were, that if they didn't do that, then we were going to get rid of them - GM 2, NBA [We were] widely criticized that we didn't pick a running back [with the second pick in the NFL draft]. But if you go back to those five principles, there was no way, unless there was no quarterback, that we were going to pick a running back. Owner 1, NFL

Artifact impact. All participants relayed examples of physical improvements that they had generated that reflect their values and concern for other members of the organization. Each 
participant mentioned specific improvements, in some cases dramatic, made to facilities that positively impacted players. More importantly, changes were a tangible example of the value that the participants placed on players. Each participant was consciously aware that the physical environment around athletes made a large impact.

One of the real key things was designing this building where the cafeteria is the center-place of the whole building. It's right in the middle, purposefully. It's right in the first floor. And it's where everybody comes together every day. And from day one in here, you had departments that never even talked to each other, barely know each other's name. You had football people having lunch with marketing people. Just the whole cross-pollination. - Owner 1, NFL We had to have the rocks out in left center field...that's neat and the fans liked it. But they were a little too brightly painted, and our left handed hitters complained and they hadn't done anything about it. So we had to raise our voices a bit and finally got some action on it. - GM, MLB

\section{Embedding New Culture}

With a steady focus on the plan, each organization eventually saw tangible signs of success, which demonstrated the validity of the new values and philosophies that the leader had brought to the organization. Success was experienced through both steady improvement and in a dramatic fashion, such as a World Series win. In both cases, success helped to embed the new values into the fabric of the organization. Embedding New Culture is composed of two subthemes: new success and turning point.

New success. Each participant eventually experienced success with his organization. This subtheme refers to slow, steady improvement which then induces renewed commitment from 
organizational members. Success was not always actualized in the form of wins, as a team sometimes noticed improvement that was not reflected in their record. Most importantly, the new success imparted a new sense of confidence in the organization along with a slow entrenchment of the leader's philosophy.

The best thing that happened early on was that we started winning more games right away, and that's healthy because it creates the sense of belief that what you're doing is right. And it started to engender confidence with the players and coaches...so the whole mentality started to shift over to the, the whole thing, 'it's the same old thing again' to 'oh, this might be something different'. - GM 1, NBA We ended up having a decent year, not a great year, didn't win anything in 2000, but had a decent year. So that got people thinking, 'hey, you know what, this is going to work'.- GM, MLB

Turning point. Occasionally, an organization came to the sudden realization that they had significantly improved, or a precipitous event transpired that collectively assisted an organization form a new world-view. It was possible for teams to experience both slow improvement, as outlined above, while also having a sudden realization that the newfound success was not fleeting.

We jumped out of the gate and beat some good teams, and then all of a sudden, we were, I don't know, 24-17 or something like that and had a chance to make a run at the playoffs. - GM 1, NBA

The day we moved into the [practice] complex was really one of the real changing of culture events. And it went from having some of the worst facilities in the NFL, to arguably the best at the time in terms of working environment. And everybody, from 
lowest level employees to superstar players, it was sort of a 'wow' moment. Owner 1, NFL

We ended up having the best record in the East [conference], we won over 50 games, we won the Eastern conference playoffs, went to the finals. - GM 2, NBA

In one instance, one participant relayed that a senior executive in his organization was removed and the impact throughout the organization when they learned that the participatn would be filling that role:

And everything changed. In fact, it just reached the field, the ticket sellers, everybody. Everybody said,' whoa, we're getting some support here, you know, this is good!'

Our Way

The fifth and final theme to emerge was Our Way, which was expressed by all six participants. This theme indicates that a culture shift had transpired and members had a new 'lens' through which to interpret the world. Our Way refers to how an organization selected members, how they made decisions, how things were run internally, and its collective values. Additionally, this extends to the new vernacular that organizational members shared, as well as any new traditions that were established.

First of all we require that everyone, we call it everyone who "touches the team", share that philosophy. They've got to embrace that [team's] philosophy. - GM, NFL Our philosophy is not that we're going to build this organization by trading. It's not the best way to build it. So we're going to hang on to our guys and all that, and let our fans connect with the guys now. - GM, MLB 
We sign a player and we talk about our philosophy here is different from...We just don't just follow a routine, because someone else did something we're going to do the same. We go with the idea of what is right. - Owner 2, NFL Our Way consists of three subthemes, including our values, better decisions and independent thought.

Our values. Expressed by all six participants, this subtheme encompasses the sentiment of valuing people within the organization, especially players, along with leadership and the fans. These values were again expressed through the decisions and actions of organizational members. For example, one participant made the decision to drop a player, but gave the player the option of where he wanted to go. When asked why he did that, the participant implicitly demonstrated his respect for the player by stating:

He'd given really good service to the team, and he deserved that.

One NFL owner essentially expressed his value in people by protecting players and coaches from poor character players:

I feel it's our responsibility to not bring in players that are like that. And we've made mistakes, but you owe it to the players you have to not bring in bad guys. Additional excerpts demonstrating the values of people, players, fans and leadership included the following:

How they feel, how they view themselves, how they view their preparation, how they approach the things that they, that they have to do to both win and be valued assets for the franchise and the community is the most important thing. - GM, NFL 
You know, talking to people, and letting them know that you value their opinion, and you have to say okay, well we don't agree with that, or we do we've got to pick it up and play it through. - Owner 2, NFL

I think our team does as good of job with the fans, trying to include fans, being fan friendly, I think we do as good as anybody. - GM 2, NBA

Better decisions. In addition to having new organizational values, the new leader, through the culture, facilitated better decisions. Five participants relayed that decisions were made according to the values of the leader and according to the organizational plan. This often applied to the type of player an organization wanted on its roster. Furthermore, members within the organization felt more confident in leadership and organizational decisions.

And once you set out on that path, you have to have a plan, and you've got to work that plan, and you can't deviate from it, unless you're convinced, and people that really know, are convinced, that deviation is the right thing to do. And those are the hardest decisions of all. - GM, NFL

Eckstein was the guy he asked waivers on, and we jumped on it. And, got him over here. I had a scouting report from one particular scout. And I said gee, if this guy's right, Eckstein might be perfect for this club. - GM, MLB

Independent thought. To remain successful, five leaders suggested that it was important for them to think "outside the box". The organization had to make a special effort to think differently from the rest of its respective league. Leaders expressed that money could not be the primary driver behind decisions, and that they had to remain adaptable and open to change while still following their blueprint. 
Because you don't want get stuck like with the same ideas that were brought in 12 years ago. We got to be that constantly innovative, looking at new ways of evaluating players, new ways of structuring areas of the operation. - Owner 1, NFL When these guys are saying that everyone's doing, this dude's doing this, I say "they're not [us], we do this thing [our] way" But we're not gonna follow because some other team does it. If we think its right we will. - Owner 2, NFL

\section{Culture Change Cycle}

The main themes and corresponding subthemes have been organized into a chronological schematic that illustrates the process of culture change in professional sport organizations as constructed by the primary investigator and the six participants, entitled the Culture Change Cycle (see Figure 1). The Culture Change Cycle serves to explain the first two research questions and will be explained in depth in the next section.

Artifact Analysis

Data for each organization, collected using the Simple Artifact Checklists (Appendix D), was compiled to further triangulate data from interviews (see Artifact Frequency Analysis; Appendix G). Additionally, artifacts within each organization were documented and linked back to one or multiple major themes.

Not surprisingly, no artifacts were found that represented Symptoms of a Dysfunctional Culture, and only one artifact, a "Perseverance” poster in a general manager's office, was found to represent My Way. Multiple items were found to represent Walk the Talk, including new practice facilities, player lounges with pool tables, video games, and TVs and cooks provided for breakfast and lunch. Numerous artifacts also represented Embedding New Culture, such as a hallway with only pictures of past Pro Bowl players and framed newspaper articles chronicling 
successes from recent seasons. Finally, artifacts such as an intentionally designed open building, the placement of a cafeteria in the center of a building, and past Lombardi (Super Bowl) trophies prominently displayed exemplified the Our Way theme.

\section{Discussion}

The primary purpose of this research was to study how leaders in professional sport changed culture. Secondary purposes were to examine whether leaders were aware of different elements of organizational culture, and to identify differences in the culture change process across sport and across roles. Through further examination of the emergent themes it became apparent that each of the above research questions was closely related. Each theme of the Culture Change Cycle can be viewed as an abstracted step in the change process and will be supported by previous research/literature.

First, a new leader arrives and witnesses the collateral damage from past leadership and poor management (Symptoms of a Negative Culture). Second, the leader implements a new way of doing things (My Way) and sets out to communicate his values, vision, and plan. The literature supports multiple subthemes in My Way. For example, explicit communication, expressed by all participants, outlined the constant formal and informal communications methods that a leader employed to articulate his plan and vision. From the perspective of individuals who have taken part in large-scale change efforts, one of the key mediators to successful culture change efforts is a high degree of communication (Covin \& Kilmann, 1990). Specifically, consistent communication on change efforts had a positive impact on followers. Conversely, Smeltzer (1991) found that a primary reason for the failure of change efforts is the presence of rumors, often predicated by the lack of timely and accurate information from leadership. Additionally, My Values was another subtheme under My Way which describes how leaders 
express their values to those around them. Lord and Brown (2001) suggest that leaders can influence the values of others explicitly through communication, or implicitly through action. More importantly, through the process of making their values known, leaders can provide a normative roadmap for acceptable behaviors within the organization (Meglino \& Ravlin, 1998).

Another subtheme from My Way that was supported in the literature was vision. Collins and Porras (1991) suggest that without a vision, an organization can only react to the future rather than create the future. Cummings and Worley (2005) indicate that creating a vision is a key component to the organizational change process. Vision must also integrate aspects of core ideology (values, purpose) and an envisioned future (dreams, hopes and aspirations). All participants suggested that their primary goal was to "win”, or "win championships”, but many added the sentiment to do it "the right way", suggesting that their values played an integral role in how they wanted to win. As Schein (1992) stated, an organization must have good reason to be receptive to a vision. Within each of these organizations, the accumulated frustration of years of mediocrity may have provided ample reasoning to embrace a new vision.

Third, through both daily and key organizational decisions, the leader repeatedly emphasizes the new values (Walk the Talk). One obvious assumption of the Walk the Talk theme is that the leader is present through the change process. In support of this process, Smith (2003) found that one of the strongest correlates to successful culture change was the presence of the sponsor throughout the entire process, and an equally strong correlate to failure was the departure of the leader or sponsor during the change process. Kotter (2007) further stated that one of the biggest mistakes leaders make in change efforts is under-communicating the vision. In essence, the day to day communication efforts that the leader makes in the Culture Change Cycle emphasizes repeatedly that the leader will not be distracted from his vision. In fact, Kotter 
(2007) used the same terminology utilized in this research when he stated that leaders learn to "walk the talk" and become a living symbol of the new corporate culture. Fourth, the organization experiences successes, both large and small (Embedding the New Culture). A primary condition for successful culture change outlined by Gagliardi (1986) was that an organization needs to collectively experience success with the new values. Finally, a new culture (Our Way), complete with new values and improved decisions, is crystallized.

\section{Culture Change as a Cycle}

The idea of culture change as a cycle is different from past conceptualizations of organizational culture change. For example, Schein (1990) utilized Kurt Lewin’s model for change (unfreeze, change, re-freeze; Kent, 2001) to suggest that the cultural change process is linear and that the resultant new culture is static. For the highly successful leaders participating in this research, a key component that has allowed their organizations to maintain success for prolonged periods is the process of introspective evaluation that each goes through at the end of each season. This process identified procedures and assumptions that were working, and those that were not. This process suggests that the resultant culture was not completely frozen. This idea was best captured by one NFL general manager:

And one of the things we always want to do is question on the mechanics of what we're doing.

The concept of adaptability and an openness to change is critical for continued organizational success and has been found to be directly correlated to organizational performance (Kotter \& Heskett, 1992; Smerek \& Denison, 2007). Kanter (1983) states unequivocally that it is not only advisable, but necessary, for an organization to innovate and change in order to keep up with both internal and external market factors. If an organization 
bypasses this introspective process, it may lead to decreased performance and a cultural fracture, as organizational members would have evidence that current values are not conducive to success. Examples of this type of failure exist across the professional sport landscape: once highly successful organizations stubbornly cling to past formulas for success. Singh (2006) suggests that this 'hubris' is a major reason that organizations become obsolete. By consistently evaluating performance and looking for ways to improve, the organization ensures that its methods remain relevant and safeguards itself against hubris. The participants in this study would suggest that this introspective process occurs within the Our Way step and is inclusive of the subtheme, independent thought.

To summarize, this introspective process then leads to a new My Way, resulting in a modified blueprint for Walk the Talk, causing new elements of culture to be engrained, which then subtly changes Our Way. In other words, subtle changes consistently refine the organization's culture and its belief of the "right way".

Although the culture change within successful sport organizations may not result in completely static culture, this does not imply that an organization does not have mechanisms in place that help maintain its present values. For example, Wallach (1983) indicated that organizations ensure there is a strong match with new employees during the hiring process, while individuals applying for membership also attempt to ensure that there is a culture match. However, as members join an organization and old members depart, the culture may undergo imperceptible changes.

Despite the Culture Change Cycle’s presentation as a clean, step-by-step process, there can be significant overlap between steps. For example, new values would not only be engrained in the Embedding New Culture step, but may also occur in the Walk the Talk step as the critical 
decisions of leaders play a large role in disseminating new values to organizational members (Schein, 1990) In fact, Schein (1990) asserts that a leader's focus, along with their reaction to critical events are two embedding mechanisms for new culture.

\section{Differences Across Roles}

No differences were identified between the cultural change process as outlined by owners as compared to those outlined by general managers. One difference of note was that one NFL owner's team had the most established culture, as the theme of Our Way was most prominent in his interview. This can be attributed to methodological errors in the criteria used for participation. In reviewing historical data, it became obvious that his organization qualified for this study on a technicality. His team met the qualifications for participation in this study in 2001. In the three years prior, the team had win-loss records of 7-9, 6-10, and 9-7, respectively. However, in each of the six seasons prior to their 1998 7-9 campaign, the team made the playoffs and had five double-digit win seasons. This illustrates that the seasons between 1998 and 2000 may have been an anomaly rather than evidence of a poor culture. The historical data, in conjunction with the interview, leads one to believe that this team's successful culture had been long established with a strong tradition, an avid fan base, and multiple Super Bowl Championship seasons. Additionally, the consistency of leadership in this participant's organization was an anomaly as compared to the other participants' organizations, where relatively recent changes in ownership had transpired.

\section{Differences Across Sport}

One major difference materialized with basketball executives, where the two participants consistently mentioned players, player acquisitions, and draft picks as significant causes for their team's turnaround, more so than executives in baseball or football. Even when asked about 
values, these participants mentioned specific player acquisitions that reflected their values. Although all involved placed a premium on talent, the general managers in basketball seemingly placed more weight on the player-personnel aspect of culture change, which fell under the My Way theme of the Culture Change Cycle.

A basketball team is smaller than both football and baseball teams. A NFL team is allowed 53 players on its active roster, with 11 players on the field at any given time. An MLB team allows 42 players, with nine players on the field in defensive situations, and only one to four players on offense, depending on base runners. In contrast, an NBA roster has 12 active players, with five on the court at any time. Each NBA player plays both offense and defense. In fact, one NBA GM stated:

Basketball is a little unique in that respect...because one player - performance wise anyway, in basketball, - can really dramatically impact a team's performance because of the small number of players and the nature of the game. Take our team now. If somehow we could go out and acquire Lebron James for some, without trading away your whole team, I mean just in theory to acquire a player like that it would dramatically impact the performance of your team.

Although no literature could be located focusing on culture change and group size, Dunbar (1996), an evolutionary psychologist, suggested that social complexity increases exponentially with group size. For example, a manager overseeing four others has to maintain four individual relationships along with six third-party relationships; in a group of 20, a manager must manage 19 direct relationships, 171 third-party relationships, and numerous 3-4 person relationships with potentially competing interests. Based on Dunbar's numbers it is arguable that culture change may be more difficult and time- 
consuming for a large group (i.e, football, baseball) than for a small group (basketball) simply because of the greater number of relationships that need to be managed, along with the greater number of individuals that need to be convinced that culture change is necessary.

\section{Limitations}

It should be noted that the Culture Change Cycle is based on the integration perspective, which is perhaps the most dogmatic view of culture as it offers little room for ambiguity (Meyerson \& Martin, 1987). Three assumptions were made in the creation of this model, which coincide with the three assumptions of the integration perspective: consistency of cultural manifestations, consensus among cultural members, and a belief that leaders create the culture. Martin (1992) suggests that a single perspective of an organization's culture could potentially be misleading. Because only the leader from each organization was interviewed, it was impossible to learn whether the meanings and values they attributed to specific cultural manifestations were consistent or shared with other members at different levels. The primary assumption, based upon performance data of the organization, was that the leader was the change agent and his values permeated the organization. The only way to verify this is to speak with other members in the organization. Although this was beyond the scope of this study, it is a potential line of inquiry for future research on organizational culture in professional sport.

Additionally, the retrospective nature of this qualitative inquiry may lend itself recallerror, which Patton (2002) suggests can be a weakness to qualitative inquiry. The most recent turning point, as outlined in the methods section, for participants in this study occurred in 2002. It is possible that the positive changes each organization has experienced could have biased participants to report the "good" things that occurred and exclude the negative 
As with most qualitative research, generalizability does not apply (Guba, 1978). However, "transferability", or the ability to find congruence in a separate context, is applicable (Lincoln \& Guba, 1985). Therefore, this research is only transferable to culture change within sport organizations that fit the context of those that participated in this research. Summary \& Future Directions

Schein (1992) states, "the bottom line for leaders is that if they do not become conscious of the cultures in which they are embedded, those cultures will manage them. Cultural understanding is desirable for all of us, but it is essential to leaders if they are to lead.” Leaders participating in this research all had an acute awareness of the cultural elements of their organization, with the commonality that each leader's respective organization has experienced a high level of success while the participant has been at the helm. Accordingly, understanding the organizational culture change process could prove beneficial for sport psychology consultants as it would provide further context for consultations. For traditional sport psychology consultations with teams and individual athletes, knowing if an organization is trying to change culture could provide valuable insight to an athlete's or a team’s struggles; knowing where an organization is in the culture change process may provide the opportunity to assist leadership in changing and embedding new values. Improved cultural understanding may also provide an avenue for new consultations with organizational leaders in sport beyond the traditional methods of working with individual athletes or coaches.

Future lines of inquiry into the culture change phenomenon would benefit from gaining the perspective of members at different levels of an organization, both vertically and horizontally, and learning whether they share a similar perspective on cultural 
meanings. Players could share insight about their view of the organization's culture, providing information that can be triangulated with senior and mid-level management across departments. An additional area of inquiry could be the comparison of the cultures within high-performing organizations with those of under-performing organizations in order to establish similarities and differences amongst leaders of both. 


\section{References}

Balthazard, P., Cooke, R., \& Potter, R. (2006). Dysfunctional culture, dysfunctional organization: capturing the behavioral norms that form organizational culture and drive performance. Journal of Managerial Psychology, 21(8), 709-732.

Collins, J. \& Porras, J. (1991). Organizational vision and visionary organizations. California Management Review, 34, 30-52.

Collins, J. \& Porras, J. (1996). Building your companies vision. Harvard Business Review, SeptOct, 65-77.

Cummings, T. \& Worley, C. (2005). Organization Development and Change, $8^{\text {th }}$ ed., SouthWestern, Madison, WI.

Dunbar, R. (1996). Grooming, gossip, and the evolution of language. Cambridge, MA: Harvard University Press.

Gagliardi, P. (1986). The creation and change of organizational cultures: A conceptual framework. Organizational Studies, 7, 117-134.

Guba, E. (1978). Toward a methodology of naturalistic inquiry in educational evaluation. CSE Monograph Series in Evaluation No. 8. Los Angeles: Center for the Study of Evaluation, University of California, Los Angeles.

Hatch, J. A. (2002). Doing qualitative research in education settings. Albany NY: State University of New York Press.

Hays, K. (2006). Being fit: The ethics of practice diversification in performance psychology. Professional Psychology: Research and Practice, 37(3), 223-232.

Helfrich, L., Mohr, Meterko \& Sales (2007). 
Kanter, R. (1983). The Change Masters: Innovation \& Entrepreneurship in the American corporation. New York: Simon \& Schuster.

Kanter, R. (2004). Confidence: Leadership and the Psychology of Turnarounds. New York: Random House Business Books.

Kent, R. (2001). Installing Change: an executive guide for implementing and maintaining organizational change, $2^{\text {nd }}$ Edition. Winnipeg, Pragma Press.

Kotter, J., \& Heskett, J. (1992). Corporate Culture and Performance. New York, The Free Press. Kotter, J. (1990). A Force for Change: How Leadership Differs from Management. New York, The Free Press.

Kotter, J. (2007). Leading change: Why transformation efforts fail. Harvard Business Review, 96-103.

Lord, R., \& Brown, D. (2001). Leadership, values, and subordinates’ self-concept. The Leadership Quarterly, 12, 133-152.

Lincoln, Y. \& Guba, E. (1985). Naturalistic Inquiry. Beverly Hills, CA: Sage.

Louis, M. (1985). An investigator's guide to workplace culture. In P. Frost. L. Moore, M. Louis, C. Lundberg, \& J. Martin (Eds.), Organizational culture (pp. 73-94). Beverly Hills, CA: Sage.

Martin, J. (1992). Cultures in Organizations: Three Perspectives. New York, Oxford University Press.

Martin, J. (2002). Organizational Culture: Mapping the Terrain. Thousand Oaks, CA, Sage Publications.

Meglino, B., \& Ravlin, E. (1998). Individual values in organizations: Concepts, controversies, and research. Journal of Management, 24(3), 351-389. 
Merriam, S. \& Associates, (2002). Qualitative Research in Practice: Examples for Discussion and Analysis. San Francisco, CA, Jossey-Bass.

Meyers, A., Coleman, J., Whelan, J. \& Mehlenbeck, R. (2001). Examining careers in sport psychology: who is working and who is making money? Professional Psychology: Research and Practice, 32(1), 5-11.

Meyerson, D., \& Martin, J. (1987). Cultural change: an integration of three different views. Journal of Management Studies, 24, 623-647.

Mills, A. (1988). Organization, gender, and culture. Organizational Studies, 9, 351-370.

Patton, M. (2002). Qualitative Research and Evaluation Methods, $3^{\text {rd }}$ Edition. Thousand Oaks, CA, Sage Publications.

Sarros, J., Gray, J. \& Densten, I. (2002). Leadership and its impact on organizational culture. International Journal of Business Studies, 10(2) 1-26.

Schein, E. (1983). The role of the founder in creating organizational culture. Organizational Dynamics, $X, 13-28$.

Schein, E. (1985). Organizational Culture and Leadership. San Francisco. Jossey-Bass.

Schein, E. (1990). Organizational culture. American Psychologist, 45(2), 109-119.

Schein, E. (1992). Organizational Culture and Leadership, $2^{\text {nd }}$ Edition. San Francisco. JosseyBass.

Singh, J. (2006). The rise and decline of organizations: can entrepreneurs’ play a saviour’s role? Vikalpa: The Journal for Decision Makers, 31(1), 123-127.

Smeltzer, L. (1991). An analysis of strategies for announcing organizational wide change. Group and Organizational Studies, 16(1), 5-24. 
Smerek, R. \& Denison, D. (2007). Social capital in organizations: Understanding the link to firm performance. Academy of Management Proceedings, 2007, 1-6.

Smith, M. (2003). Changing an organisations’s culture: correlates of success and failure. Leadership and Organizational Development Journal, 24, 249-261.

Wallach, E. (1983). Individuals and organizations: the culture match. Training and Development Journal, 2, 29-36.

Williams, J., \& Straub, W. (2001). Sport Psychology: Past, Present, Future. In J.Williams (Ed.) Applied Sport Psychology: Personal Growth to Peak Performance, $4^{\text {th }}$ ed. (pp.112).Mountain View, CA: Mayfield Publishing Co.

Zaichkowsky, L. \& Naylor, A. (2005). Sport psychology foundations, organizations, and related resources. Journal of Applied School Psychology, 21(2), 9-24. 
Table 1. Participant Team Information

\begin{tabular}{|c|c|c|c|c|c|c|c|c|c|c|}
\hline League & Year & Team & Wins & Losses & Ties & Win \% & Win\%Incr & Qualify? & Owner & General Manager \\
\hline NFL & 1995 & $\mathrm{NFL}$ & 9 & 7 & 0 & 0.563 & & & & \\
\hline $\mathrm{NFL}$ & 1996 & NFL & 9 & 7 & 0 & 0.563 & 0 & & & \\
\hline $\mathrm{NFL}$ & 1997 & $\begin{array}{l}\mathrm{NFL} \\
\end{array}$ & 3 & 13 & 0 & 0.188 & -0.375 & & & \\
\hline $\mathrm{NFL}$ & 1998 & NFL & 3 & 13 & 0 & 0.188 & 0 & & & \\
\hline $\mathrm{NFL}$ & 1999 & $\mathrm{NFL}$ & 13 & 3 & 0 & 0.813 & 0.625 & $x$ & & \\
\hline $\mathrm{NFL}$ & 2000 & $\mathrm{NFL}$ & 10 & 6 & 0 & 0.625 & -0.188 & $x$ & & \\
\hline NFL & 2001 & NFL & 6 & 10 & 0 & 0.375 & -0.25 & $x$ & & \\
\hline $\mathrm{NFL}$ & 2002 & $\mathrm{NFL}$ & 10 & 6 & 0 & 0.625 & 0.25 & & & \\
\hline $\mathrm{NFL}$ & 2003 & $\mathrm{NFL}$ & 12 & 4 & 0 & 0.75 & 0.125 & $x$ & & \\
\hline $\mathrm{NFL}$ & 2004 & $\mathrm{NFL}$ & 12 & 4 & 0 & 0.75 & 0 & $x$ & & \\
\hline $\mathrm{NFL}$ & 2005 & $\mathrm{NFL}$ & 14 & 2 & 0 & 0.875 & 0.125 & & & \\
\hline $\mathrm{NFL}$ & 2006 & NFL & 12 & 4 & 0 & 0.75 & -0.125 & & & \\
\hline $\mathrm{NFL}$ & 2007 & $\mathrm{NFL}$ & 13 & 3 & 0 & 0.813 & 0.063 & & & \\
\hline $\mathrm{NFL}$ & 1995 & $\mathrm{NFL}$ & 10 & 6 & 0 & 0.625 & & & & \\
\hline $\mathrm{NFL}$ & 1996 & $\mathrm{NFL}$ & 10 & 6 & 0 & 0.625 & 0 & & & \\
\hline $\mathrm{NFL}$ & 1997 & $\mathrm{NFL}$ & 6 & 9 & 1 & 0.406 & -0.219 & & & \\
\hline NFL & 1998 & $\mathrm{NFL}$ & 3 & 13 & 0 & 0.188 & -0.218 & & & \\
\hline $\mathrm{NFL}$ & 1999 & $\mathrm{NFL}$ & 5 & 11 & 0 & 0.313 & 0.125 & & & \\
\hline $\mathrm{NFL}$ & 2000 & $\mathrm{NFL}$ & 11 & 5 & 0 & 0.688 & 0.375 & $x$ & & \\
\hline $\mathrm{NFL}$ & 2001 & NFL & 11 & 5 & 0 & 0.688 & 0 & $x$ & & \\
\hline $\mathrm{NFL}$ & 2002 & $\mathrm{NFL}$ & 12 & 4 & 0 & 0.75 & 0.062 & $x$ & & \\
\hline $\mathrm{NFL}$ & 2003 & NFL & 12 & 4 & 0 & 0.75 & 0 & $x$ & & \\
\hline $\mathrm{NFL}$ & 2004 & NFL & 13 & 3 & 0 & 0.812 & 0.062 & $x$ & & \\
\hline $\mathrm{NFL}$ & 2005 & $\mathrm{NFL}$ & 6 & 10 & 0 & 0.375 & -0.437 & & & \\
\hline NFL & 2006 & NFL & 10 & 6 & 0 & 0.625 & 0.25 & & & \\
\hline $\mathrm{NFL}$ & 2007 & NFL & 8 & 8 & 0 & 0.5 & -0.125 & & & \\
\hline $\mathrm{NFL}$ & 1995 & $\mathrm{NFL}$ & 11 & 5 & 0 & 0.688 & & & & \\
\hline $\mathrm{NFL}$ & 1996 & NFL & 10 & 6 & 0 & 0.625 & -0.063 & & & \\
\hline $\mathrm{NFL}$ & 1997 & NFL & 11 & 5 & 0 & 0.688 & 0.063 & & & \\
\hline $\mathrm{NFL}$ & 1998 & $\mathrm{NFL}$ & 7 & 9 & 0 & 0.438 & -0.25 & & & \\
\hline $\mathrm{NFL}$ & 1999 & $\mathrm{NFL}$ & 6 & 10 & 0 & 0.375 & -0.063 & & & \\
\hline NFL & 2000 & NFL & 9 & 7 & 0 & 0.563 & 0.188 & & & \\
\hline
\end{tabular}




\begin{tabular}{|c|c|c|c|c|c|c|c|c|c|c|}
\hline League & Year & Team & Wins & Losses & Ties & Win \% & Win\%Incr & Qualify? & Owner & General Manager \\
\hline NFL & 2001 & $\mathrm{NFL}$ & 13 & 3 & 0 & 0.812 & \#REF! & $x$ & & \\
\hline NFL & 2002 & NFL & 10 & 5 & 1 & 0.656 & -0.156 & $x$ & & \\
\hline NFL & 2003 & $\mathrm{NFL}$ & 6 & 10 & 0 & 0.375 & -0.281 & & & \\
\hline NFL & 2004 & $\mathrm{NFL}$ & 15 & 1 & 0 & 0.938 & 0.563 & $x$ & & \\
\hline NFL & 2005 & NFL & 11 & 5 & 0 & 0.688 & -0.25 & $x$ & & \\
\hline $\mathrm{NFL}$ & 2006 & $\mathrm{NFL}$ & 8 & 8 & 0 & 0.5 & -0.188 & & & \\
\hline $\mathrm{NFL}$ & 2007 & $\mathrm{NFL}$ & 10 & 6 & 0 & 0.625 & 0.125 & & & \\
\hline NBA & 1995 & NBA & 39 & 43 & 0 & 0.476 & & & & \\
\hline NBA & 1996 & NBA & 39 & 43 & 0 & 0.476 & 0 & & & \\
\hline NBA & 1997 & NBA & 34 & 48 & 0 & 0.415 & -0.061 & & & \\
\hline NBA & 1998 & NBA & 27 & 55 & 0 & 0.329 & -0.086 & & & \\
\hline NBA & 1999 & NBA & 27 & 23 & 0 & 0.54 & 0.211 & $x$ & & \\
\hline NBA & 2000 & NBA & 44 & 38 & 0 & 0.537 & -0.003 & $x$ & & \\
\hline NBA & 2001 & NBA & 55 & 27 & 0 & 0.671 & 0.134 & $x$ & & \\
\hline NBA & 2002 & NBA & 61 & 21 & 0 & 0.744 & 0.073 & $x$ & & \\
\hline NBA & 2003 & NBA & 59 & 23 & 0 & 0.72 & -0.024 & $x$ & & \\
\hline NBA & 2004 & NBA & 55 & 27 & 0 & 0.671 & -0.049 & $x$ & & \\
\hline NBA & 2005 & NBA & 50 & 32 & 0 & 0.61 & -0.061 & & & \\
\hline NBA & 2006 & NBA & 44 & 38 & 0 & 0.537 & -0.073 & & & \\
\hline NBA & 2007 & NBA & 33 & 49 & 0 & 0.402 & -0.135 & & & \\
\hline NBA & 1995 & NBA & 30 & 52 & 0 & 0.366 & & & & \\
\hline NBA & 1996 & NBA & 30 & 52 & 0 & 0.366 & 0 & & & \\
\hline NBA & 1997 & NBA & 26 & 56 & 0 & 0.317 & -0.049 & & & \\
\hline NBA & 1998 & NBA & 43 & 39 & 0 & 0.524 & 0.207 & & & \\
\hline NBA & 1999 & NBA & 16 & 34 & 0 & 0.32 & -0.204 & & & \\
\hline NBA & 2000 & NBA & 31 & 51 & 0 & 0.378 & 0.058 & & & \\
\hline NBA & 2001 & NBA & 26 & 56 & 0 & 0.317 & -0.061 & & & \\
\hline NBA & 2002 & NBA & 52 & 30 & 0 & 0.61 & 0.293 & $x$ & & \\
\hline NBA & 2003 & NBA & 49 & 33 & 0 & 0.598 & -0.012 & $x$ & & \\
\hline NBA & 2004 & NBA & 47 & 35 & 0 & 0.573 & -0.025 & $x$ & & \\
\hline NBA & 2005 & NBA & 42 & 40 & 0 & 0.512 & -0.061 & & & \\
\hline NBA & 2006 & NBA & 49 & 33 & 0 & 0.598 & 0.086 & & & \\
\hline
\end{tabular}




\begin{tabular}{|c|c|c|c|c|c|c|c|c|c|c|}
\hline League & Year & Team & Wins & Losses & Ties & Win \% & Win\%lncr & Qualify? & Owner & General Manager \\
\hline NBA & 2007 & NBA & 41 & 41 & 0 & 0.5 & \#REF! & & & \\
\hline MLB & 1995 & MLB & 78 & 67 & 0 & 0.538 & & & & \\
\hline MLB & 1996 & MLB & 70 & 91 & 0 & 0.435 & -0.103 & & & \\
\hline MLB & 1997 & MLB & 84 & 78 & 0 & 0.519 & 0.084 & & & \\
\hline MLB & 1998 & MLB & 85 & 77 & 0 & 0.525 & 0.006 & & & \\
\hline MLB & 1999 & MLB & 70 & 92 & 0 & 0.432 & -0.093 & & & \\
\hline MLB & 2000 & MLB & 82 & 80 & 0 & 0.506 & 0.074 & & & \\
\hline MLB & 2001 & MLB & 75 & 87 & 0 & 0.463 & -0.043 & & & \\
\hline MLB & 2002 & MLB & 99 & 63 & 0 & 0.611 & 0.148 & $\times$ & & \\
\hline MLB & 2003 & MLB & 77 & 85 & 0 & 0.475 & -0.136 & $\times$ & & \\
\hline MLB & 2004 & MLB & 92 & 70 & 0 & 0.568 & 0.093 & $\times$ & & \\
\hline MLB & 2005 & MLB & 95 & 67 & 0 & 0.586 & 0.018 & $\times$ & & \\
\hline MLB & 2006 & MLB & 89 & 73 & 0 & 0.549 & -0.037 & $\times$ & & \\
\hline
\end{tabular}


Table 2. Reflection of Schein’s (1983) Five Principles in Interview Protocol

\begin{tabular}{|c|c|c|}
\hline \multicolumn{2}{|c|}{ Organizational Culture Principle } & $\begin{array}{l}\text { Protocol Question } \\
\text { Reflecting principle }\end{array}$ \\
\hline \multirow{5}{*}{$\begin{array}{l}\text { Schein's five } \\
\text { principles of } \\
\text { organizational } \\
\text { culture }\end{array}$} & Organization's relation to the environment & $2 b, 2 c$ \\
\hline & The nature of truth & 3,4 \\
\hline & The qualities of human nature & $9,2 \mathrm{a}$ \\
\hline & The nature of human activity & 9,3 \\
\hline & The nature of human relationships & $2 \mathrm{a}$ \\
\hline \multicolumn{2}{|c|}{$\begin{array}{l}\text { Organizations lessons from critical incidents (Schein, } \\
\text { 1983) }\end{array}$} & 5,8 \\
\hline \multicolumn{2}{|c|}{$\begin{array}{l}\text { Kanter's (2004) three cornerstone's of success } \\
\text { (collaboration, initiative, accountability) }\end{array}$} & $3,4,6,7$ \\
\hline \multicolumn{2}{|c|}{ Schein (1990) Unfreeze, Change, Freeze } & $4,6,7,8$ \\
\hline
\end{tabular}




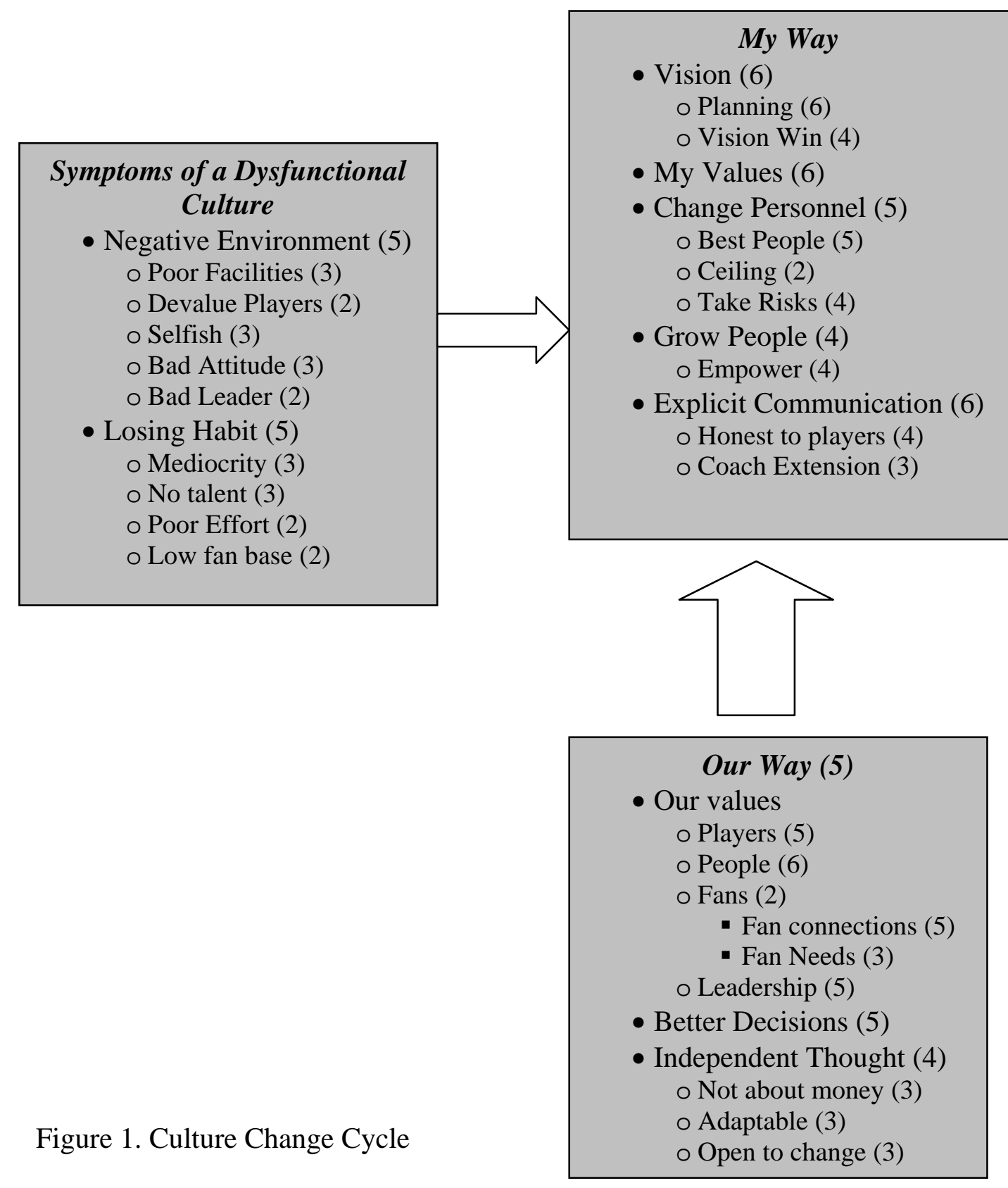

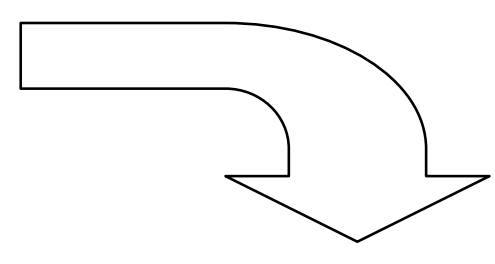

Walk the Talk (6)

- Day to Day (3)

- Obstacles to Change (5)

- Media Pressure (4)

o Repetition (4)

- Critical Events (5)

- Artifact Impact (6)

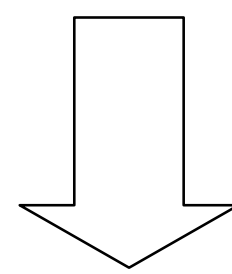

Embedding New Culture(5)

- Turning Point (5)

- New Success (6)

o Buy-In (4)

o Confidence (3)

o Engrained Philosophy (3)

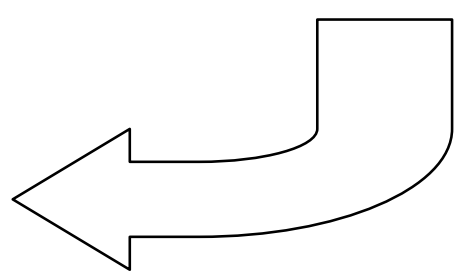


Organizational Culture Change in Sport 47

Appendix A

Brief Participant Biography 
Note: Content redacted as information would identify participants.

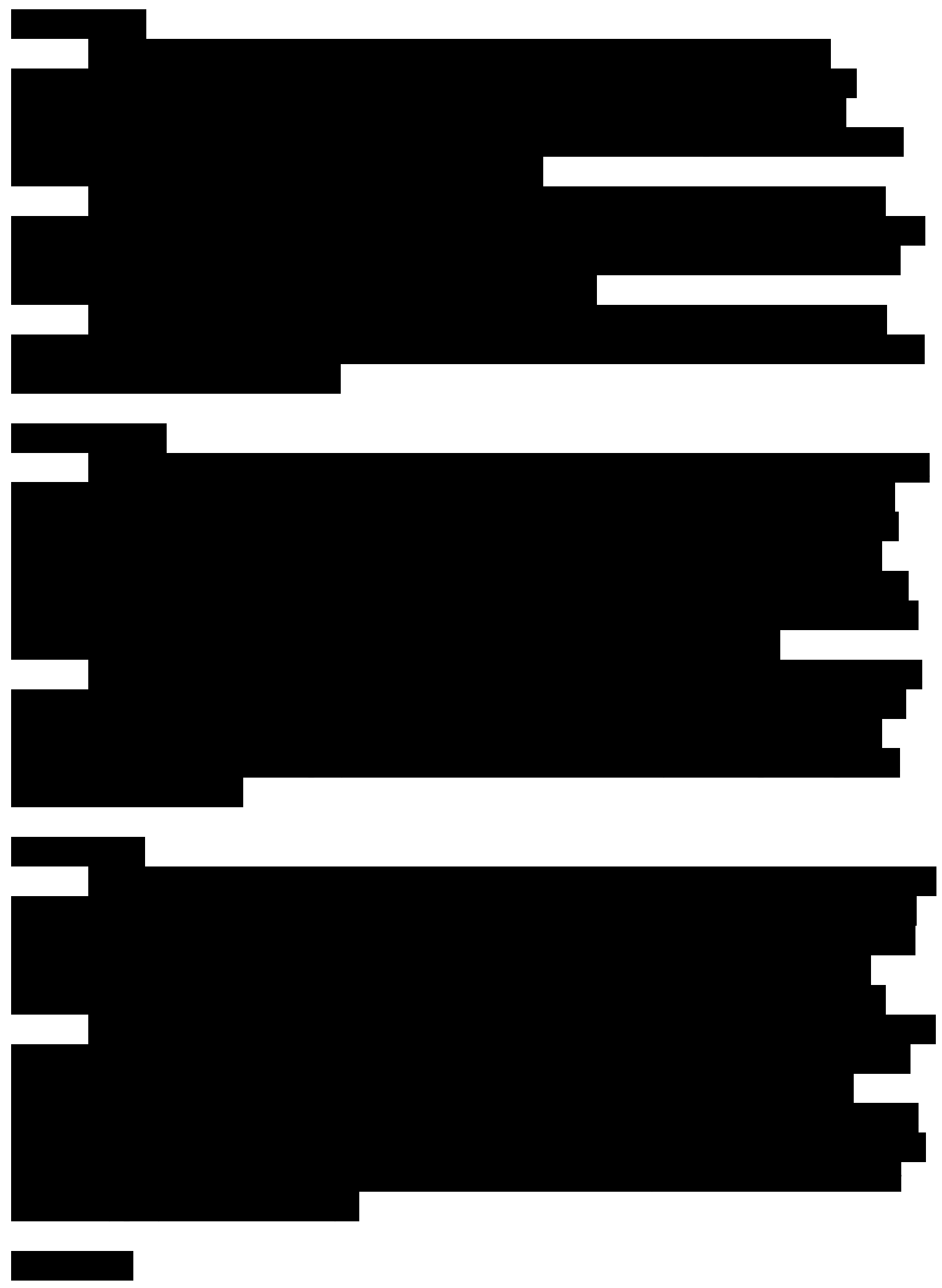


Organizational Culture Change in Sport 49

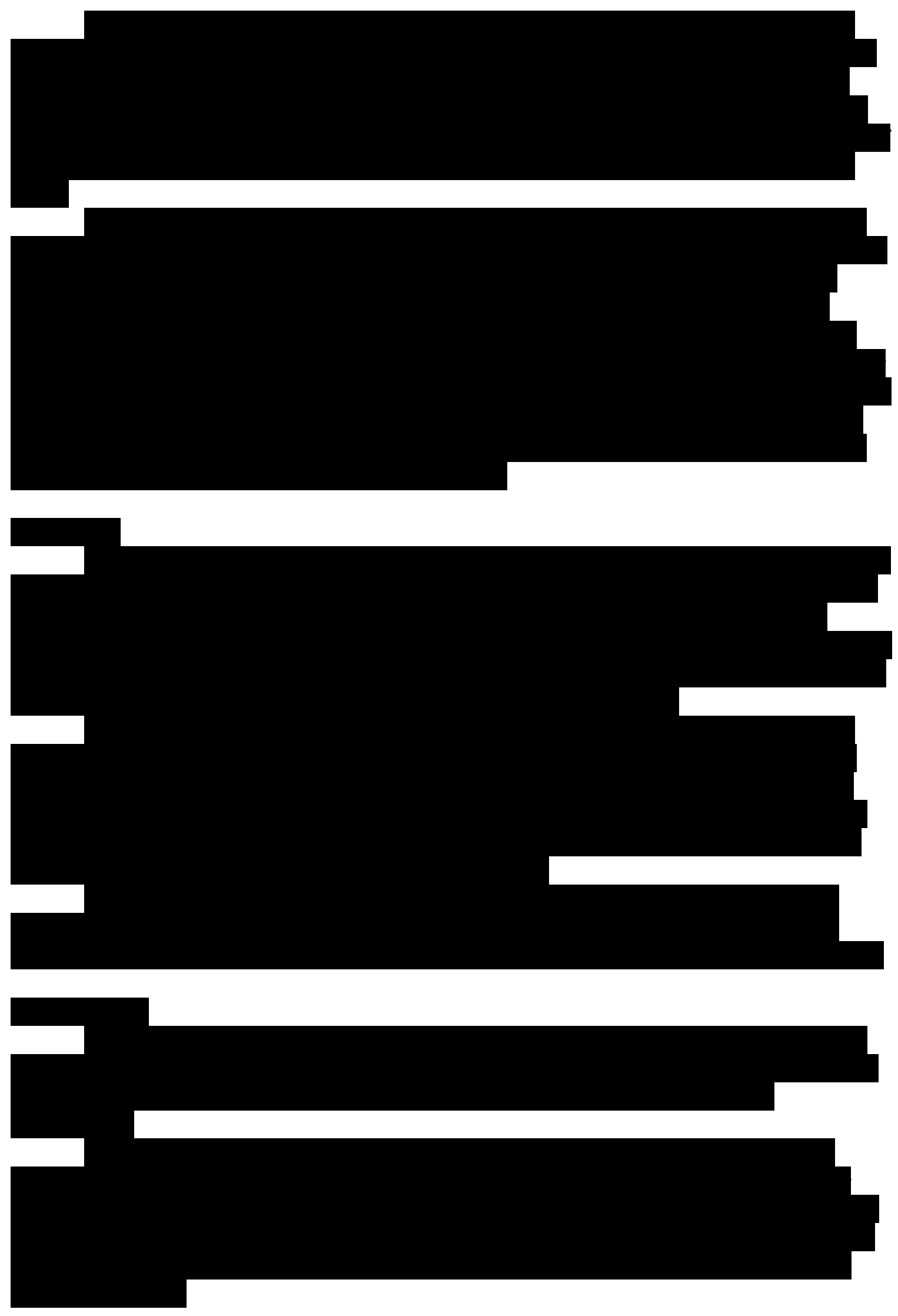


Organizational Culture Change in Sport 50

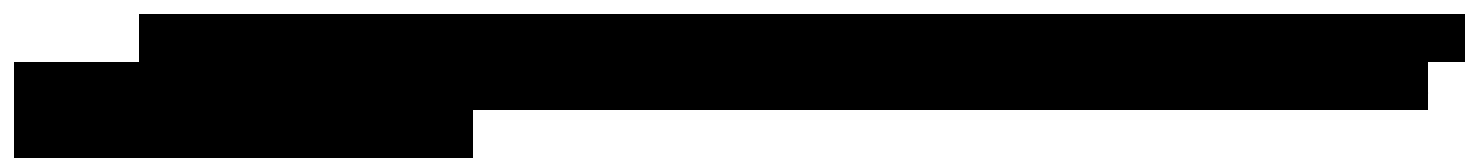


Organizational Culture Change in Sport 51

Appendix B

Interview Protocol 


\section{Script for Study}

Good morning/afternoon/evening, thank you for participating in this research study. The purpose of the study is to determine how executives in professional sport have successfully brought their franchises through culture change. I would like to audiotape this interview in order to accurately represent what you say; may I have your permission to tape this interview? Before we begin I want to make sure you understand the following:

- Because of these questions, and the high-profile nature of professional sport, your name may be disclosed.

- Your participation is entirely voluntary, you can choose to stop the interview at any time and you do not have to answer every question.

Thank you again for your willingness to participate in this study.

1. Tell me about your background. How did you get to where you are now?

2. Describe the values in this organization when you arrived?

a. How did people treat one another?

b. What was the organizations relationship with the fans?

c. What was the organizations relationship with the players?

3. How was the culture affecting performance?

4. How did you communicate that change was necessary?

5. What were other [organizational decision-makers] perceptions of the changes that needed to be made

6. Looking back over the early phase of your tenure in this position, what would you describe as the critical events that required you to demonstrate your leadership and your values? How did you deal with these events?

7. What was your vision for this organization?

8. How did you communicate that vision to others?

- Those you work with

- Athletes

- Fans

- League

9. Can you describe some early successes that you believe were able to persuade the rest of the organization that your vision was realistic?

10. How are your values now reflected in this organization?

11. Can you point to any specific physical changes/documents that can be attributed to you?

12. Is there anything I haven't asked about that you think I should know? 
Organizational Culture Change in Sport 53

Appendix C

Cover Letter to Participants 


\section{Dear Participant,}

Thank you for agreeing to participate in this study. The purpose of this research is to gather information about leadership and organizational culture change in professional sport. I am conducting this research as a final requirement to achieve my $\mathrm{PhD}$ in Sport \& Exercise Psychology. The interview contains questions about your experiences, as a leader, in implementing culture change throughout an organization. This interview will take approximately 1-1.5 hours to complete. Your participation is voluntary and you do not have to answer every question. You may also stop your participation at any time without penalty.

As a public figure, there is no guarantee of confidentiality, as it is likely identifying information will be provided by you in the interview. If you have questions about the study, you may contact Joe Frontiera at (304) 685-6522. For information about your rights as a research subject, you may call the Office of Research Compliance at (304) 293-7073. West Virginia University’s IRB acknowledgement of this study is on file.

Thank you for your participation in this important project.

Sincerely,

Joe Frontiera, M.S.

jfrontie@mix.wvu.edu

Sport \& Exercise Psychology Doctoral Student

West Virginia University

School of Physical Education

P.O. Box 6116

Morgantown, WV 26506
Jack Watson, Ph.D

Jack.watson@mail.wvu.edu

Associate Professor, Dissertation Chair 
Organizational Culture Change in Sport 55

\section{Appendix D}

\section{Simple Artifact Checklist}




\begin{tabular}{|l|l|l|l|}
\hline \multicolumn{1}{|c|}{ Item } & Yes & No & \\
\hline Stadium & & & \\
\hline Practice Facility & & & \\
\hline Locker Room & & & \\
\hline Coach's Offices & & & \\
\hline Executives Offices & & & \\
\hline Cafeteria & & & \\
\hline Player Lounge & & & \\
\hline Strength \& \\
Conditioning Room
\end{tabular}


Organizational Culture Change in Sport 57

Appendix E

Researcher's Bias of Organizational Culture 
At a relatively young age, I have been a part of both productive and exciting organizational cultures, as well as stagnant, de-motivating organizational cultures. My first job after college was with a mid-size technology company. There, the environment was invigorating. I was able to learn on a daily basis, my colleagues were consistently supportive, and the management continually communicated successes, new product launches, and they were able to foster an environment of healthy competition. We consistently interacted with the management at different regional and national events. It was obvious they valued our opinions and contributions, as our suggestions were often made policy. Additionally, our organization took a consultative sales approach, one in which we valued the needs of our customers and tried to meet those needs. If we couldn’t, we maintained the relationship but suggested they go in a different direction.

About one year into my tenure, the mid-size company I started with was bought by WorldCom. At the time, WorldCom had been making many acquisitions in order to bolster its technological capabilities and revenue stream. However, even at my level, it was obvious that there was a great deal of in-fighting occurring on a regular basis. Individuals within this conglomerate organization were striving to maintain the power they held in their former organizations, while at the same time trying to meet the expectations of unrealistic quotas and demands from upper-management. Additionally, WorldCom wanted its sales associates to push their products hard, regardless of the needs of their customers. Their sales force reflected this attitude, and it was often personally and professionally embarrassing to go on joint sales calls with WorldCom representatives. 
The once close office that I had started with began to disintegrate. The competitive, invigorating environment that we had all thrived upon would not return. Individuals began working fewer hours, and often were involved in less productive activities while in the office. The amount of "process paperwork" grew exponentially. The sense of control that we had once felt about our own destiny within the organization was gone. I, along with others, felt powerless. My opinion was not valued, and my contributions were not recognized. We continually heard how well our new organization was doing, but these accomplishments rang false, so we assumed the success was coming from other areas of this $\$ 30$ billion dollar company. Rarely did we see or hear from management. Instead, we heard horror stories from those who were forced to deal with management. Where our motivation was once competition, it was now fear.

Only after I departed did I learn that WorldCom was under investigation by the Securities and Exchange Commission (SEC). In 2002, the company was forced to declare bankruptcy - the largest filing in the history of the US. Both the founder and CFO were convicted of securities fraud and conspiracy, among other charges.

The contrasts of these two cultures helped shape my view of both positive and negative cultures. A positive culture is one which all contributors’ opinions are valued; employees feel empowered to share their ideas; employees are consistently learning and developing; and there is cross-communication throughout levels and divisions of the organization. A negative culture is one in which only a minority feel empowered; employees count the hours of the day until its time to punch out; communication is topdown; and employees rarely take initiative or go above the standard call of duty as they know the risks far outweigh the benefits. 
These are my own biases, and it is critical for me to remain cognizant of these biases throughout the interview process and the data evaluation process. 
Organizational Culture Change in Sport 61

Appendix F

Codebook 


\begin{tabular}{|c|c|}
\hline Code Word & Definition \\
\hline \multicolumn{2}{|l|}{ arent Code: } \\
\hline BADBASICS & Poor fundamentals \\
\hline BADCULTURE & Bad Culture - evidence \\
\hline BEACON & Example team to rest of respective league. \\
\hline COMRADERIE & Sense of working on a team. Working with others. \\
\hline DYSCULTURE & Symptoms of a Dysfunctional Culture \\
\hline EMBCULTURE & Embed new culture \\
\hline FOUNDER & Founder of organization. \\
\hline FRMLMGMT & Formal Management Training \\
\hline FUTURE & Future of organization... \\
\hline GOODOFLEAG & Good of overall league \\
\hline INCFANBASE & Increased fan base \\
\hline LDCONFIDEN & Leader being confident in himself and his plan \\
\hline LONGINVOLV & Long involvement - referring to an individual's involvement in sport. \\
\hline LUCK & Luck \\
\hline MODELING & Leaders modeling behavior \\
\hline MYWAY & My way- the leader's belief in his way of doing things. \\
\hline OPENACCESS & Open access to leader \\
\hline OURWAY & Our way. The idea that the organization's way is the best way. \\
\hline \multicolumn{2}{|l|}{ PERSIST } \\
\hline RELUCLDR & Reluctant Leader \\
\hline RESPONBITY & Responsibility \\
\hline TEAM & Team environment \\
\hline TOP DOWN & Idea that philosophies are disseminated from the top. \\
\hline UNIQUE & Unique aspect of interview \\
\hline VAL SPORT & Value Sport in General \\
\hline VALBASICS & Value Fundamentals \\
\hline VALCHEMIST & Value Chemistry \\
\hline \multicolumn{2}{|l|}{ VALDIVERSE } \\
\hline VALYOUTH & Value Youth \\
\hline WALKTHTALK & Idea that you don't just say you want to win, but you also do what needs to be done to accomplish goals \\
\hline \multicolumn{2}{|r|}{ 1 } \\
\hline DEVAPLAYER & Devalue Players \\
\hline NO TRUST & No Trust \\
\hline NOHONESTY & Lack of honesty \\
\hline NOINTEGRIT & Lack of integrity \\
\hline VAL $\$ \$ \$ \$$ & Value Money above all Else \\
\hline \multicolumn{2}{|c|}{ arent Code : BAD LEADER } \\
\hline AVOIDTEAM & Good people avoid the team due to existing culture \\
\hline BADATTITUD & Bad attitude \\
\hline FEAR & Fear as an aspect of a culture \\
\hline LDRPRESSUR & Pressure (negative) from the leader \\
\hline \multicolumn{2}{|l|}{ arent Code : BEACON } \\
\hline LONGTRMWIN & Long term win - sustained success \\
\hline \multicolumn{2}{|c|}{ arent Code : BESTPEOPLE } \\
\hline CREDIBILE & Credibility - past playing experience \\
\hline GOODPEOPLE & Good people in organization - or good people needed for organization to run well. \\
\hline PASSION & Passion - having intense interest in a job, sport, etc. \\
\hline POSATTITUD & Positive Attitude \\
\hline \multicolumn{2}{|l|}{ arent Code : CEILING } \\
\hline MINEXPER & The idea that experience is not as important as most people make it out to be. \\
\hline \multicolumn{2}{|c|}{ arent Code: CHPERSONEL } \\
\hline BESTPEOPLE & Attempt to bring on best people in organization. \\
\hline CEILING & A person's potential \\
\hline TAKE RISKS & Taking risks in order to achieve \\
\hline \multicolumn{2}{|l|}{ arent Code : DAYTODAY } \\
\hline ORGBARRIER & Organizatioanal Barriers \\
\hline REPITITION & Reptitively communicating same message \\
\hline \multicolumn{2}{|c|}{ arent Code : DYSCULTURE } \\
\hline LOSING HBT & Losing Habit \\
\hline NEGENVIRON & Negative environment \\
\hline \multicolumn{2}{|c|}{ arent Code : EMBCULTURE } \\
\hline \multicolumn{2}{|l|}{ NEWSUCCESS } \\
\hline TURNING PT & Turning Point \\
\hline \multicolumn{2}{|c|}{ arent Code: EXPLCOMMUN } \\
\hline COACHEXTEN & Idea that the coach is the extension of organizational leaders, and communicates their values to the team/athletes. \\
\hline HONESTPLAY & Communicating honestly to players. \\
\hline
\end{tabular}




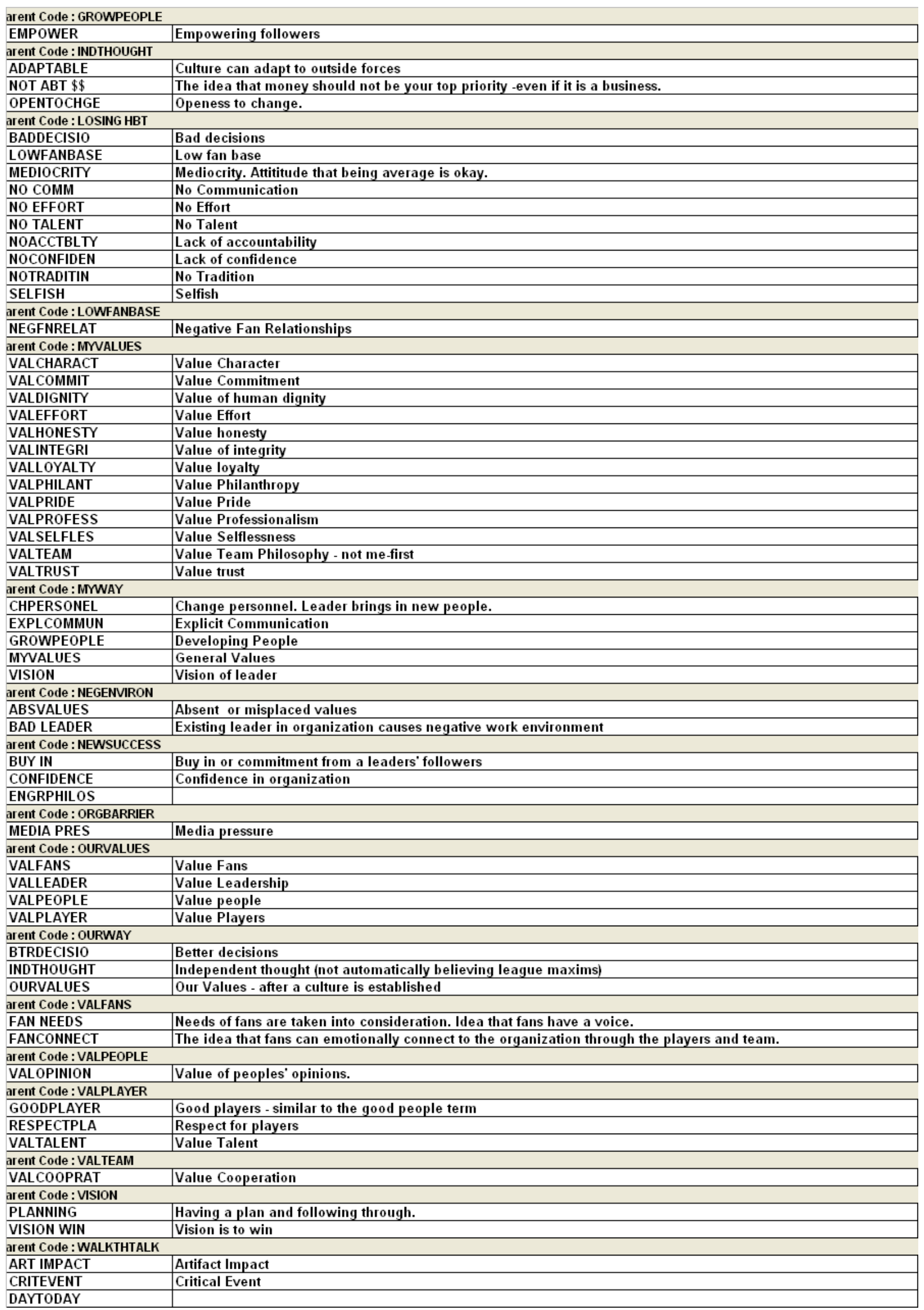


Organizational Culture Change in Sport 64

Appendix G

Artifact Frequency Analysis 
Artifact Frequency Analysis

\begin{tabular}{|c|c|c|c|c|c|c|c|}
\hline Item & Team 1 & Team 2 & Team 3 & Team 4 & Team 5 & Team 6 & Total \\
\hline Stadium & $\mathrm{X}^{*}$ & $\mathrm{X}$ & $\mathrm{X}^{*}$ & $\mathrm{X}^{*}$ & $\mathrm{X}^{* *}$ & $\mathrm{X}^{*}$ & $6 / 6$ \\
\hline Practice Facility & 1 & $\mathrm{X}^{*}$ & $\mathrm{X}^{*}$ & $\mathrm{X}^{*}$ & $\mathrm{X}^{* *}$ & $\mathrm{X}^{*}$ & $5 / 6$ \\
\hline Locker Room & X & $X$ & $X$ & $X$ & $X$ & $X$ & $6 / 6$ \\
\hline Coach's Offices & $X$ & $X$ & $X$ & $X$ & $X$ & $\mathrm{X}$ & $6 / 6$ \\
\hline Executives Offices & $X$ & $X$ & $X$ & $X$ & $X$ & $X$ & $6 / 6$ \\
\hline Cafeteria & $X$ & $X$ & $X$ & $\mathrm{X}$ & $X$ & $\mathrm{X}$ & $6 / 6$ \\
\hline Player Lounge & $X$ & $X$ & $X$ & $X$ & $X$ & $X$ & $6 / 6$ \\
\hline $\begin{array}{l}\text { Strength \& } \\
\text { Conditioning Room }\end{array}$ & $X$ & $X$ & $\mathrm{X}$ & $X$ & $X$ & $\mathrm{X}$ & $6 / 6$ \\
\hline $\begin{array}{l}\text { Prominent Quotes } \\
\text { On Display }\end{array}$ & & $\mathrm{X}$ & $\mathrm{X}$ & $\mathrm{X}$ & $\mathrm{X}$ & $\mathrm{X}$ & $5 / 6$ \\
\hline Quotes on Display & $X$ & $X$ & $\mathrm{X}$ & $X$ & $X$ & $X$ & $6 / 6$ \\
\hline Statues/Busts & & & & & & $X$ & $1 / 6$ \\
\hline Rehab Facilities & $X$ & $X$ & $\mathrm{X}$ & $X$ & $X$ & $X$ & $6 / 6$ \\
\hline On Display & & & & & & & \\
\hline
\end{tabular}

* Indicates facility built since 2000

** Indicates plans to build new facility 
Specific Links to the Culture Change Cycle Model

Team 1

\begin{tabular}{|l|l|c|c|c|c|c|}
\hline Artifact & Notes & SDC & MW & WTT & ENC & OW \\
\hline Locker Room & Improved lighting, new carpet & & & $\mathrm{X}$ & $\mathrm{x}$ & $\mathrm{X}$ \\
\hline Stadium & Repainted rocks for left-handed hitters & & & $\mathrm{X}$ & & $\mathrm{X}$ \\
\hline Quotes & Framed newspapers from recent seasons & & & & $\mathrm{x}$ & $\mathrm{x}$ \\
\hline On Display & Wall of Fame - mostly recent players & & & & $\mathrm{x}$ & $\mathrm{x}$ \\
\hline
\end{tabular}

Team 2

\begin{tabular}{|l|l|c|c|c|c|c|}
\hline Artifact & Notes & SDC & MW & WTT & ENC & OW \\
\hline Prac. facility & Two full courts, jersey of past greats & & & $\mathrm{x}$ & & \\
\hline Prac. facility & Separate media area & & & & & $\mathrm{x}$ \\
\hline Player lounge & Pool table, video games, tv & & & $\mathrm{x}$ & & $\mathrm{x}$ \\
\hline Rehab & Steam room, spa, rehab pool & & & $\mathrm{x}$ & & $\mathrm{x}$ \\
\hline Quotes & "It's not about you”, “Thank Him” & & & $\mathrm{x}$ & & $\mathrm{x}$ \\
\hline
\end{tabular}

Team 3

\begin{tabular}{|l|l|c|c|c|c|c|}
\hline Artifact & Notes & SDC & MW & WTT & ENC & OW \\
\hline Prac. Facility & Indoor field, two outdoor fields, 2002 & & & $\mathrm{x}$ & $\mathrm{x}$ & \\
\hline Locker Room & Moonroof, natural light, ground floor & & & $\mathrm{x}$ & $\mathrm{x}$ & $\mathrm{x}$ \\
\hline Cafeteria & Middle of building, open communication & & & $\mathrm{x}$ & $\mathrm{x}$ & $\mathrm{x}$ \\
\hline Quotes & Rosa Parks, MLK, J. Salk & & & $\mathrm{x}$ & & $\mathrm{x}$ \\
\hline Rehab & Top of the line equipment & & & $\mathrm{x}$ & & $\mathrm{x}$ \\
\hline
\end{tabular}


Team 4

\begin{tabular}{|l|l|c|c|c|c|c|}
\hline Artifact & Notes & SDC & MW & WTT & ENC & OW \\
\hline $\begin{array}{l}\text { Exec Offices } \\
\text { Display }\end{array}$ & Perseverance poster & & $\mathrm{x}$ & & & \\
\hline Prac. facility & New, no stairs, huge banner & & & $\mathrm{x}$ & & $\mathrm{x}$ \\
\hline Locker room & No media access, new ice baths, & & & & & $\mathrm{x}$ \\
\hline Cafeteria & Serve breakfast/lunch to players, family & & & $\mathrm{x}$ & & $\mathrm{x}$ \\
\hline New construct & $\begin{array}{l}\text { Extend executive and coaching offices, } \\
\text { something new every year }\end{array}$ & & & & $\mathrm{x}$ \\
\hline On display & $\begin{array}{l}\text { Pro-Bowl hall: All pro-bowl players in } \\
\text { history }\end{array}$ & & & $\mathrm{x}$ & $\mathrm{x}$ & $\mathrm{x}$ \\
\hline Player lounge & Super Bowl pics, leather chairs, foozball & & & $\mathrm{x}$ & & $\mathrm{x}$ \\
\hline
\end{tabular}

Team 5

\begin{tabular}{|l|l|c|c|c|c|c|}
\hline Artifact & Notes & SDC & MW & WTT & ENC & OW \\
\hline Pract Facility & Well lit, banners, EC Champs & & & & & $\mathrm{x}$ \\
\hline On display & Eastern conference champs & & & & & $\mathrm{x}$ \\
\hline Cafeteria & Breakfast and lunch orders taken by cook & & & & & $\mathrm{x}$ \\
\hline On display & NJ Nets “Plan to Win" & & & $\mathrm{x}$ & $\mathrm{x}$ & $\mathrm{x}$ \\
\hline Quotes & Ali quote “run on the long road” & & & & & $\mathrm{x}$ \\
\hline Quotes & "winning about effort” V. Carter & & & $\mathrm{x}$ & & \\
\hline
\end{tabular}

Team 6

\begin{tabular}{|c|c|c|c|c|c|c|}
\hline Artifact & Notes & SDC & MW & WTT & ENC & OW \\
\hline Prac. Facility & New indoor, outdoor facility & & & $\mathrm{X}$ & & $\mathrm{X}$ \\
\hline Statues & Joe Greene - past great & & & & & $\mathrm{X}$ \\
\hline Cafeteria & Simple, clean, small & & & & & $\mathrm{X}$ \\
\hline Exec Offices & Lots of open spaces to promote comm. & & & & & $\mathrm{X}$ \\
\hline Trophies & $\begin{array}{l}\text { Five Lombardi Trophies - prominent } \\
\text { placement }\end{array}$ & & & & & $\mathrm{x}$ \\
\hline On display & $\begin{array}{l}\text { Hall of Fame wall - all players through } \\
\text { Steeler's history that have made HOF }\end{array}$ & & & & & $\mathrm{x}$ \\
\hline
\end{tabular}


Organizational Culture Change in Sport 68

\section{Appendix $\mathrm{H}$}

Review of Literature 


\section{REVIEW OF THE LITERATURE}

\section{Introduction}

Organizational culture is a relatively abstract concept that has yet to be examined in the context of sport. The purpose of this review of literature is to give the reader a primer on the many different aspects of organizational culture. The construct will not only be defined, but the different methods of assessing organizational culture will be discussed. Furthermore, the impact of leadership on organizational culture will be examined, and the relationship between culture and performance will be explored. The literature has been consistent on the existence of a relationship between culture and performance (Kotter \& Heskett, 1992; Smerek \& Denison, 2007).

It is important to understand the above elements prior to examining the reasons behind culture decline and, more importantly, the ways in which a "broken” culture might be repaired. Throughout this process, a case will be constructed for the addition of organizational culture awareness and culture change into the more traditional sport psychology interventions.

\section{Organizational Culture}

The terms "culture” and "climate” are often used interchangeably, and there is considerable confusion within the literature about what each of these constructs describe. For example, McMurray (2005) stated that climate is a stable characteristic of a company that distinguishes it and “embodies members” collective perceptions about their organization with respect to autonomy, trust, cohesiveness, support, recognition, innovation and fairness” (p. 1). Unlike McMurray, Falcione and Kaplan (1984) posited 
that culture persists over time, while climate is a snapshot of the same elements at any given moment in time. Climate is also thought to be quantifiable (measurable) while culture is more qualitative.

Denison (1996) argued that culture and climate simply represent different perspectives of organizational environments, and that they may not be truly different concepts. For example, culture requires an emic perspective while climate requires an etic perspective; culture requires qualitative analysis while climate requires quantitative analysis; culture is underlying values and assumptions while climate is the surface manifestations of those values and assumptions; and, culture is rich and dependent upon an organization's history, while climate is ahistorical in nature. Similar to Denison’s perspective, and for the purpose of clarity within this literature review, the differences between culture and climate lie with individual perception (Ashworth, 1985). Both climate and culture reside on the same continuum; members are consciously aware of climate, while culture is a phenomenon of unconscious beliefs.

In sport, organizational culture has not yet been examined. However, a similar concept has - climate. Ames (1992) defined climate as the environment that a coach creates within his or her team. Ames suggested that there are primarily two types of climates: mastery or ego-involving. A mastery climate is one in which a coach defines success as giving maximum effort, consistent skill improvement, and persisting through adversity. In contrast, an ego involving climate is one in which athletes are encouraged to compare themselves to one another, mistakes are punished, and winning is the primary emphasis. 
Ames’ (1992) definition of climate is markedly different than Schein’s construct of organizational culture, ostensibly due to the fact that Ames has studied climate only in the context of the sport team. However, there are additional reasons for the differences. For example, whether a coach creates a mastery or ego-involved climate primarily affects the focus of the players. In contrast, organizational culture is more subtle and pervasive, and impacts all members of an organization, regardless of job task or level. Secondly, climate is learned primarily through dealing with an individual - the coach.

Organizational culture can be learned through the observance of how any member of an organization deals with issues of external adaptation or internal integration. Finally, an outsider would likely be able to determine what type of climate an athletic team has by watching a single practice. Organizational culture is more subtle. Only a very perceptive outsider would be able to determine the complexities of the values and underlying assumptions that comprise an organization's culture, and this would be a difficult task to accomplish in a single day.

Smith and Smoll (1997) used Ames approach to climate to create Coach Effectiveness Training (CET), a system to assist coaches increase awareness of their own specific behaviors that lead to a mastery climate. These behaviors include reframing “winning”, positive reinforcement, the establishment of norms which encourage athletes to help and support one another, and involving athletes in decisions regarding team rules. In one study, 31 little league baseball coaches were randomly assigned to either the experimental group (received CET training) or the control group (no training). Results indicated that CET trained coaches gave more reinforcement for effort, responded to mistakes with encouragement, were better liked, and were rated as better teachers. More 
importantly, players had a significantly higher self esteem and lower dropout rate (5\%) than those in the control group (26\%).

Despite a thorough review of literature and evidence of the positive impact of specific interventions on sport climate, there is a dearth of published literature examining organizational culture and sport. Lee, Wagstaff, Fletcher, and Hanton (2007) encouraged the convergence of mainstream business literature and sport psychology literature. One of the ten business dimensions Lee et al identified that needs to be explored in sport was organizational culture. Lee and colleagues implied that discrepancies within an overall culture might impose unnecessary demands on the athletes and therefore impact performance.

While climate has been discussed in the context of sport, and culture has been compared to climate, it is critical to clearly define organizational culture. Most sport psychology consultants likely have only a vague idea of organizational culture of the teams, departments and organizations they work for, as training in this area is not a part of the traditional educational curriculum for sport psychology.

Organizational culture came into vogue in the early 1980s to explain the failures of US companies relative to their Japanese counterparts (Schein, 1990). Perhaps the most well-known scholar of organizational culture is Edgar Schein. Schein admits that culture is a difficult construct to define, as it has its roots in sociology, anthropology, and organizational behavior (Schein, 1992). Similar to Ashworth (1985), Schein claims that climate is a "surface manifestation" of culture, which is defined as:

a pattern of shared basic assumptions that the group learned as it solved its problems of external adaptation and internal integration, that has 
worked well enough to be considered valid and, therefore, to be taught to new members as the correct way to perceive, think, and feel in relation to these problems. (p. 12)

Schein $(1990,1992)$ identified three different levels of culture: observable artifacts, values, and basic underlying assumptions. As the term implies, observable artifacts are aspects of an organization that any outsider would easily be able to see. For example, dress code, the manner in which individuals address one another (formally, informally, etc.), and publicized mission statements are all considered observable artifacts. The second level of culture, the shared values of an organization, is not as easily observed. These need to be determined through interviews. For example, if integrity is valued within a sales organization, multiple interviews would reveal this through employees stated interactions with customers and co-workers. Interviews would reveal that the employee finds it important to keep his/her word on deliverables to customers. However, if money/status is the value, this likewise would be revealed through interviews with subtle clues, including the lack of respect for another sales person's territory.

The third and perhaps most difficult level of culture to determine is the basic underlying assumptions of an organization. These are typically unconscious and can only be discerned through intense observations and in-depth questions (Schein, 1990). Continuing with the examples above, if integrity is the value, an underlying assumption may be that honesty leads to success, or that true success does not exist without honesty within human interactions. Likewise, if money/status is the value, the underlying assumption may be that competitive aggressiveness will drive individuals and the 
company to be as successful as they possibly can. Those that are not competitive and/or aggressive will weaken the organization.

Research has indicated that culture has an impact on organizational performance (Kotter \& Heskett, 1992), employee behavior (Kilman, Saxton \& Serpa, 1985), cohesion (Gagliardi, 1986), employee turnover (Sheridan, 1992), job satisfaction (Lok \& Crawford, 2003) and self-esteem (Dutton, Dukerich \& Harquail, 1994). However, culture can also impact communication barriers and power struggles (Kanter, 1983) and resistance to change (Gagliardi, 1986).

Assessment of Culture

Schein (1990) pointed out that because of the largely unconscious nature of culture, it is difficult to measure. The difficulty arises primarily because survey research assumes knowledge of the correct dimensions, and is therefore largely inadequate as a means of "measuring” culture. Additionally, analytical-descriptive research fragments the holistic concept of culture; ethnographic and historical research is time consuming and expensive; clinical descriptive (data gathered while a consultant is helping the system) leaves out the breadth. Schein states that the best way to determine an organization's culture is through determining what layer is most prominent, conducting interviews to determine values while looking for anomalies, and pushing past those values to determine underlying assumptions. This process is most effective when the interviewer has a combination of insider knowledge and outsider perspective.

However, all researchers do not agree that culture should not be assessed quantitatively. Colyer (2000) compared the different cultures of five Australian sport associations, using the Quinn Instrument II (Quinn \& Spreitzer, 1991) as the quantitative 
measure. The Quinn Instrument II uses the Competing Values Framework (CVF) as its theoretical basis. The CVF was developed in the early 80s, from an integration of theories and factors that were thought to contribute to organizational effectiveness. The CVF posits that most organizations can be assessed along two dimensions, each representing competing methods to solving basic challenges that all organizations must overcome in order to function.

The first dimension, or set of competing values, is an organization's penchant for encouraging centralized control over organizational processes, versus an organization's proclivity to value decentralization and flexibility. The second dimension is the organization's orientation towards its internal environment and processes versus its orientation towards its external environment and relationships with outsiders.

To fully understand Colyer's (2000) research, it is important to comprehend the the four resultant quadrants of the CVF. Helfrich, Li, Mohr, Meterko, and Sales (2007), describe these quadrants as:

1. Bureaucratic culture (Internal focus, emphasis on control). These organizations adopt centralized authority over organizational processes, have respect for a formal hierarchy, and adhere to rules. Stability and predictability are valued.

2. Team cultures (Internal focus, emphasis on flexibility): These organizations encourage broad participation, teamwork and empowerment, and value human resource development.

3. Entrepreneurial culture (External focus, emphasis on flexibility) These organizations foster creativity and innovativeness and place a premium on growth and expansion. 
4. Rational culture (External focus, emphasis on control): These types of organizations are characterized by clarity of tasks and goals, with an emphasis on efficiency and measurable outcomes.

These four cultures are prototypes, and organizations tend to have elements of each as part of their overall culture. Each culture type is assessed by four questions using a Likert-type scale ranging from 1 to 5 . A graphical representation of the culture can be created by placing the score for each culture type on a diagonal axis and connecting the four resultant points, creating an object of varying size and shape. A larger object indicates a stronger overall culture.

Due to a small response rate, Colyer (2000) was able to compare only three of the five sport organizations’ cultures. For the four scales, Cronbach’s alpha were as follows: team (.88), developmental (.86), bureaucratic (.58), rational (.85). The author suggests that the CVF may be a good diagnostic tool to use along with qualitative methods to assess culture.

Although Colyer (2000) found the use of the CVF adequate, Helfrich et al. (2007) utilized factor analysis to assess whether the instrument was valid in the health care industry. Analysis revealed a better fit for a two-factor model (parsimony) rather than the classic four-factor CVF. The entrepreneurial, rational and team scales combined to form one scale. Since their sample was non managers $(\mathrm{N}=77,776)$, their study raises questions about the CVF's usefulness in health care and amongst non managers.

The above analysis of the CVF indicates, as Schein $(1990,1992)$ suggested, that when culture is assessed quantitatively assumed values may not accurately measure the values that an organization deems important. The CVF inherently limits the types of 
cultures and values that an organization might embrace. Furthermore, a quantitative assessment does not necessarily capture the underlying assumptions of the organization. Although use of the Quinn Instrument II may provide an adequate starting point for cultural diagnosis, in isolation it limits the potential depth of cultural analysis. Organizational Culture Formation: The Impact of Leadership

With a working knowledge of organizational culture and its assessment, it is important to explore how culture initially forms and is passed from generation to generation. Schein (1983) posits that culture is a combination of the assumptions and theories of the founder, along with what the organization learns from its own unique experiences. Accordingly, there are five seemingly philosophical tenets from which a culture paradigm is formed.

The first is the organization's relationship to its environment (dominance, submission, harmonizing, a niche, etc). The second tenet is the nature of truth within that organization. This is determined through answering the question, "how is truth ultimately determined?” The third tenet is the qualities of human nature within the organization. To determine human nature, it is important to understand what it means to be human, and what attributes are valued (aggressiveness, harmony, organization, creativity). The fourth tenet is the nature of human activity which evolves from an organization's collective belief in what the right thing is for human beings to do. This is determined by the assumptions of reality, the environment, and human nature. For example, the nature of "human activity" is going to be markedly different within a non-profit organization than a highly competitive sales organization. The final tenet revolves around the nature of human relationships. This is dictated by an organization's belief of the "right way" for 
people to interact with each other. To best understand this, it is important to assess how power and love are distributed, and whether life is collaborative or competitive, based on laws and regulation or on charisma.

These tenets are developed through what leaders role model, what they pay attention to, and how they react to critical events. Schein $(1990,1992)$ believes that culture is created around critical incidents. Specifically, the immediate next set of behaviors after an incident begins to create a norm, through identification with leaders. Additional methods in which a culture can be reinforced are through organizational design, systems and procedures, physical layout and design, the stories, myths and legends that are emphasized, and formal statements of organizational philosophies, such as mission or vision statements (Schein, 1990).

Although Schein was convinced that leadership influenced culture, Sarros, Gray and Densten (2002) attempted to determine the causal factor in the leadership-culture relationship. They administered the Multifactor Leadership Questionnaire (MLQ Form 5x; Bass \& Avolio, 1997) and the Organizational Culture Profile (OCP; O’Reilly, Chatman, \& Caldwell, 1991) to 1918 executives in Australia. The MLQ measures elements of transactional and transformational leadership, such as idealized attributes, idealized behaviors, inspirational motivation, and intellectual stimulation. The OCP measures organizational culture orientations along eight factors, including innovation, attention to detail, outcome orientation, aggressiveness, supportiveness, emphasis on rewards, team orientation, and decisiveness.

Multiple regression analysis was used to determine if the above aspects of leadership predicted the different elements of organizational culture, or whether aspects 
of culture influenced leadership. The authors found that different elements of leadership had a moderate impact on culture, with a variance ranging from $14 \%-24 \%$. Conversely, culture had less of an impact on leadership, with the variance of $4 \%-10 \%$.

When examining these findings in more detail, Sras and his fellow researchers found that a transactional leadership style accounted for $24 \%$ of the variance of cultural aspect of emphasis on rewards (i.e., fair behavior which rewards and praises good work performance, and provides opportunities for professional growth); the leadership quality of supportiveness accounted for $23 \%$ of the variance of the cultural aspect of inspirational motivation; the leadership quality of innovation accounted for $20 \%$ of the variance of the cultural aspect of both inspirational motivation and contingent reward; and the leadership style of competitiveness accounted for $18 \%$ of the variance of the cultural aspect of inspirational motivation and contingent rewards.

In summary, Sarros and his colleagues’ work largely supported the supposition of Schein - that leadership leads to culture. However, their findings cannot be interpreted in a dichotomous manner, as they also suggested that culture has an impact on leadership. Additionally, the culture that leaders help to form is reinforced by the experience of the organization and whether the leader's way has been effective in the organization's ability to deal with crisis (Schein, 1983). For a successful first generation organization, one of the main dilemmas is how to successfully transition the culture in a way that preserves it and at the same time ensures that the organization remains adaptive to its alwayschanging external environments. This conscious dilemma implicitly implies that the initial culture of an organization positively impacts the organization's performance.

\section{Culture and Performance}


This implicit implication of a definitive relationship between culture and performance has been debated by scholars of organizational culture. Kotter and Heskett (1992), widely seen as the preeminent experts on the relationship between culture and performance, have made a compelling case that culture does impact performance. They outline three general theories of culture: the strong culture, the strategically appropriate cultures, and the adaptive culture.

Over the span of four years, Kotter and Heskett (1992) analyzed performance metrics for hundreds of organizations. First, they classified each organization into one of three culture types. The first of these, the strong culture, is one in which the organization has an evident, notable style. In other words, employees are aligned and motivated to do their jobs in a specific manner. These cultures are easily identifiable to the outside world, as evidenced by the "IBM Way" in business, or the New York Yankees in sport where athletes must adhere to a strict dress code and carry themselves professionally on and off the field. To test the relationship between strong cultures and performance, Kotter and Heskett (1992) administered culture strength indices and examined economic performance measures for 207 organizations from a wide variety of industries and locations. They found that there was a general positive correlation between strength of corporate culture and market value $(r=.26)$, net income growth $(r=.46)$, and return on average investment ( $r=.31)$. However, these correlations were relatively weak and lacked consistency. For example, it is possible to have a strong culture with bad performance, so a strong culture may include “dysfunctional elements” that may be a detriment to performance. In fact, most of the organizations that had a strong culture but weak 
performance often had a prior history of success, indicating that the organization held onto a culture past the time of its effectiveness.

The second culture type that was examined was the strategically appropriate culture, or a culture that is effective only if it fits within its current internal and external environment. For example, a culture with slow decision making and a lot of bureaucracy would not be an appropriate fit for a dot com company in the Silicon Valley, where change occurs rapidly. Only a culture strategically appropriate, or one that fits within its current external environment, will facilitate a strong performance. Kotter and Heskett (1992) selected 22 of the original 207 companies from 10 different industries, each of which had outperformed the overall industry. Each sample company was matched with a company that underperformed as compared with its industry.

The researchers then took a qualitative approach and interviewed members of all organizations, questioning whether they thought their culture helped performance, hurt performance, both helped and hurt it, had no impact on performance, and whether their respective culture fit the market. To add further depth to their data, they had participants answer the same questions using a Likert-type scale. Overwhelmingly, those in companies that had lower performance felt that their company’s culture hurt their performance and did not fit their industry, while those in higher performing organizations felt their culture helped their performance and was a good fit for their industry. The main criticism of this theory is that external environments change, and often the culture of a company remains the same. When the culture-environment discrepancy grows, performance may suffer. 
The final culture theory type examined was the adaptive culture. The adaptive culture takes into account environmental change. This type of culture helps members anticipate and adapt to environmental change; the only cultures that will perform well are those that continually and successfully adapt. As cited in Kotter and Heskett (1992),

Kilmann, Saxton and Serpa (1985) described and adaptive culture as one that: entails a risk-taking, trusting, and proactive approach to organizational as well as individual life. Members actively support one another's efforts to identify all problems and implement workable solutions. There is a shared feeling of confidence: the members believe, without a doubt, that they can effectively manage whatever new problems and opportunities will come their way. There is a widespread enthusiasm, a spirit of doing whatever it takes to achieve organizational success. The embers are receptive to change and innovation. (p. 44)

This change-embracing culture must come from leadership, and the adaptive culture must value leadership (Kotter, 1990). The leadership, in turn, must value the core constituencies of the organization: customers, stockholders and employees. The adaptive cultures theory states that the higher performing organizations values all three of the constituents. Because the managers care deeply about the constituencies, they pay close attention to them, their needs, and the environment. When changes amongst or within constituents occur, managers are quick to spot the trend and make the appropriate changes to align their strategy with the new conditions.

Using the same 22 organizations from the study above, Kotter and Heskett (1992) asked the question "how much does the culture value excellent leadership from its 
managers?” using a Likert-scale from 1 (low) to 7 (high). Higher performing firms averaged 6, while lower performing firms averaged 3.9. Furthermore, higher performing firms valued their customers $\left(M_{\text {higher }}=6.0 ; M_{\text {lower }}=4.6\right)$, employees $\left(M_{\text {higher }}=5.8 ; M_{\text {lower }}\right.$ = 4.1) and stockholders $\left(\mathrm{M}_{\text {higher }}=5.7 ; \mathrm{M}_{\text {lower }}=3.9\right)$ significantly more than the lower performing firms.

In summary, this information implies that there is lack of leadership directing an organization's focus on salient issues in lower performing organizations. Additionally, this also may indicate that employees within these organizations who may be focused on salient issues (customers, employees, stockholders) may feel that their actions will fail to make a difference. More importantly, this information indicates that there is a positive relationship between organizations that focus outwardly on customers and stockholders and internally on employees and leadership.

Because each of the above studies is correlational in nature, it is difficult to say that culture causes performance, or performance causes culture. Yet, through their qualitative analysis, Kotter and Heskett (1992) make a strong case that a pattern of success emerges when managers care about their constituencies, pay attention to them, and quickly recognize when changes are occurring at those levels. They then use leadership, which is highly valued, to drive changes (reduce costs, improve products, culture modification) until they again have adapted to their environments.

By applying Kotter and Heskett’s concept of culture to professional sport organizations, it is easy to identify franchises that neatly fit in the mold of each of the three cultures. For example, the Oakland Raiders (2008) have a strong culture that mirrors the identity of its owner, Al Davis. He has always been a maverick, often suing 
the league and picking up players that other teams have deemed as “problems”. He has also stubbornly held on to his "long ball” philosophy, despite the major changes occurring in the league at large with the embracement of the West Coast offense, zone blitzes and salary caps. At one time, his strategy was successful. However, he has held onto his philosophy, ignoring two of the three elements of his constituents: his fans (customers) and his players and coaches (employees). Despite the Raiders strong culture, the organization is largely ineffective in today’s NFL.

In summary, there seems to be a strong link between culture and performance. In order to create or maintain an adaptive culture, the owner or general manager of a sport organization must focus on core constituents: their employees (athletes and coaches), their customers (fans), and their stockholders (owners). In doing this the team has a greater chance of achieving success, as leadership will quickly recognize and adapt to changes that are occurring throughout the league within which they compete. When cultures go bad

Now that culture-performance link has been established, it is necessary to explore why cultures go bad and the types of culture that do not facilitate successful performance. Singh (2006) suggests that the average lifespan of an organization has been shrinking steadily, and is now roughly 35 years. This lifespan is likely to shrink further in the near future, as changes continue to occur at a faster pace.

Along with lifespan, there are four broad reasons why organizations eventually become obsolete (Singh, 2006). For one, the organization is overwhelmed by external changes. Often, the strategies that organizations implement become obsolete due to external environmental changes. Whether the change revolves around consumer 
preference, the behavior of competitors, technology, or governmental policies, these changes can be major and they can occur quickly. Secondly, inertia may hold organizations to the formula of past success. Third, both hubris and complacency take hold. Pride essentially blinds members to competitive pressures and changes to the external environment. Finally, once an organization realizes that a major change is needed, they underestimate the difficulty of implementing change. Instead, they try to push ideas through resistance as quickly as possible, rather than empowering employees and selling them on the idea that if the status quo is maintained, their organization will no longer be relevant.

In her book The Change Masters, Kanter (1983) discussed organizations that were close to becoming obsolete. She identifies the cultures existing within these companies as "segmentalist”. A segmentalist culture is one in which barriers are placed, both intentionally and inadvertently, between the different units of an organization. Once this occurs, collaboration is reduced or eliminated, and power is concentrated amongst a few individuals or levels. Once a segmentalist culture develops, little communication takes place between departments, and the prime motivator for members is securing power for themselves or their department. Because of this, each unit works solely through their respective boss, causing "silos" to form throughout the company.

Within these organizations, management uses control rather than empowerment to direct their employees. Often, elaborate bureaucratic processes develop, along with centralized decisions and a one-way flow of communication (top-down). When employees are not empowered, risk-taking is eliminated as there is a general intolerance 
of failure. This intolerance results in employees conforming to the status quo - which may have been successful in the past but will eventually become ineffective.

Kanter (1983) takes the stance that it is necessary for any organization to innovate and change - to keep up with both internal and external market factors. Within a segmentalist organization, there are three factors that make innovation difficult. For one, it is less likely that an innovator will overcome the barriers that inherently exist within the organization. For example, an innovator may experience difficulty obtaining enough power to even present an idea. Secondly, it is not likely that an innovation that does make it will be taken advantage of by the particular unit within which it was developed. After all, this could displace the current power structure. Finally, if an innovation does stick, it is unlikely that a segmentalist organization will have the internal communication networks to transfer the innovation throughout the company so that the entire organization can reap the benefits of the change.

In addition to inherent challenges with innovation, two traps are common within segmentalist organizations (Kanter, 1983). The first has been coined the "bureaucratic trap”. This occurs when there is a sense of powerlessness, which generates the need to defend one's territory. Often times, this defense leads to an inherent resistance to other's good ideas. The second trap, the entrepreneurial trap, is the perceived need to be the source of a good idea within an organization. This leads members to push their own ideas forward and ignore others, to the detriment of the organization.

Other theories abound about dysfunctional cultures. In the popular trade book, The Five Dysfunctions of Team, Lencioni (2002) develops a model in which each of five dysfunctions builds upon one another until you have a thoroughly dysfunctional 
organization. The first dysfunction is an absence of trust, or an unwillingness to be open with team members. Once this occurs, the second dysfunction, a fear of conflict, develops. When conflict is absent, it becomes difficult to commit to an idea because few have voiced their opinions, regardless of whether the opinions are filled with dissent or agreement. The fourth dysfunction that naturally follows is an avoidance of accountability. After all, if you do not fully commit to an idea, it is difficult to hold yourself or your peers accountable. And finally, when there is little accountability, the result is an inattention to results, which Lencioni claims occurs when team members put individual needs and division needs above the collective needs and goals of the team.

Kanter's (2004) work has supported Lencioni’s theory of team dysfunction. In her book about leadership, confidence and the psychology of turnarounds, she says along with a natural shelf life, denial can be a large virus that impacts organizations that are accustomed to winning. It's easy to deny that there is a problem and that the market may have changed. Denial can erode what Kanter calls the three cornerstones of success: collaboration, initiative and accountability. This denial may stem from dysfunctional assumptions within the culture that "operate as silent filters of what is perceived and thought about” (p. 78). Further confidence erodes when employees retreat to protect their own "turf", which can be considered their power, their direct reports or their own product line. This cycle of decline is solidified when organizations begin to encounter "doom loops”. Kanter (2004) defines doom loops as:

Decline generally does not stem from a single factor, but from an accumulation of decisions, actions, and commitments that become entangled in self-perpetuating system dynamics. Once a cycle of decline 
is established, it is hard to simply call a halt, put on the brakes and

reverse direction. The system has momentum. Expectations have

formed, and they can turn into a culture that perpetuates losing. (p. 95)

Kanter claims that when there are few resources or coping mechanisms for dealing with problems within an organization, employees fall back on almost primitive selfprotective behavior. Nine common pathologies begin to unfold, as an emotional and behavioral chain reaction: communication decreases; criticism and blame increases; respect decreases; isolation increases; focus turns inward; rifts widen and inequities grow; initiative decreases; aspirations diminish; negativity spreads.

Furthermore, similar to an ego oriented athlete who knows s/he can not win, an environment is cultivated and reinforced that discourages employees from trying to impact change. After all, why try to change a situation when the belief persists that there will be no impact? In fact, Kanter (2004) believes that "sports teams may be relatively simple examples, but the dynamics of losing streaks in sports illuminated issues of failure in more complex systems” (p. 138).

\section{Culture Change}

Each of the authors in the above section agreed that when a culture goes bad, change become necessary. These changes are often complex, difficult and take a significant amount of time. In fact, an entire academic field, change management, has evolved focusing on how to successfully create change within organizations. Although that field focuses on implementing changes of process or technology, altering culture is subtly different and places more emphasis on the human element. 
Culture change has its roots far before the advent of organizational psychology. Phelan (2005) compares the eight-step process of organizational change developed by Kotter and Heskett (1992) to the anthropologic concept of revitalization. Kotter and Heskett's model is as follows:

1. Initial Culture: The initial culture develops, which leads to success.

2. Aberrant behavior: New managers, not aware or in agreement with the existing culture, exhibit behavior that conflicts with the established cultural norms or vision (arrogance, lack of values, resistance to change).

3. New Leadership, New Vision: A new CEO is hired who identifies the crisis, and develops a vision to lead the organization from that crisis.

4. Reorganization: This new leader maintains a high visibility and models the new acceptable behavior.

5. Successful culture change: Because the new actions achieve desired results, employees are motivated to change their behavior. Furthermore, norms and values also begin to change.

In anthropology, the concept of cultural revitalization has many parallels. Cultural revitalization is a "movement that involves establishing new religious or political ideologies in societies that are threatened by cultural crisis” (p.49).

1. Steady state period - the existing culture operates in an acceptable manner.

2. Period of increased individual stress: Economic distress, epidemic, politics or war is a catalyst that enlightens people that the traditional manner of dealing with stress is no longer effective. 
3. Period of Revitalization: A prophet or visionary comes forth with a plan (often given by a supernatural being) that presents a culturally relevant goal. This plan includes communication, reorganization, adaptation, routinization, and finally a new steady state.

It is evident that organizational cultural change is not a novel concept. It has its origins in the larger cultural changes that have occurred throughout our history. Applying these two models to professional sport, its easy to see how an organization can have prolonged success followed by economic hardship, poor management, or the failure to deal with external changes. Once this occurs, new ownership or management comes in with a specific plan to make the team relevant again. A great example of this is the San Francisco 49ers. Throughout the 80s and early 90s, they were arguably the most successful team in the National Football League. Issues with their upper management and ownership, and arrogance from their past success, left the franchise reeling, both financially and from a coaching and talent standpoint. However, over the past five years, a new general manager and coach have introduced specific goals under a comprehensive plan in an attempt to make the team relevant again.

In the early $20^{\text {th }}$ century, Kurt Lewin, a physicist turned psychologist, developed a three-step model of change. Lewin believed that in order for successful systemic change to occur, it is necessary to unfreeze the current system, make the change, and refreeze the new system (Kent, 2001). However, most systems ignore the first and third steps. When these steps are ignored, the change will most likely fail.

Schein (1990) asserts that Lewin’s three step process needs to occur in order to successfully change culture. First, leaders need to "unfreeze" the present system by 
outlining and discussing impending threats to the organization if no change occurs. Secondly, a new direction needs to be formalized along with a new set of assumptions. This second step is the actual "change". At times, it is necessary to inject outsiders into the system who have not been acculturated by the past system. New rituals and artifacts need to be created in order to emphasize the "new way". Finally, members of the organization need to be positively reinforced when their actions align with the new assumptions, and punished when they adhere to old assumptions. In severe cases, groups that hold tightly to the old culture need to be disbanded. This third step is "refreezing" the new culture.

Not only do organizations inadvertently skip the "unfreeze" and "refreeze" steps, but Kotter and Haskett (1992) assert that culture is difficult to change because both the interdependence between and within levels of culture (i.e., values and behaviors), and the interdependence between the culture and the power structure. Additionally, there is a strong connection between human emotions and values. There are also multiple ways in which a culture sustains itself and resists change. Examples of this are the stories that are told repeatedly within organizations to remind members of the organization's values. A second example is the selection criteria used for new members. Wallach (1983) adds that along with the organization, individuals applying for membership also attempt to ensure that there is a culture match. Therefore, both the organization and the new members work together to ensure that the culture remains the same.

Gagliardi (1986) suggests that there is a relatively simple explanation for the strong resistance to culture change within an organization. When a culture change is necessary, it is usually because the values and assumptions that were once effective in 
dealing with organizational crises are no longer effective. However, values and their underlying assumptions are not open for discussion or criticism. Gagliardi posits that there is a four stage process for ingraining these values. The first phase occurs when a leader shares his/her vision. Typically, this vision is a set of beliefs including a causeeffect relationship. If the behaviors oriented by the basic beliefs lead to the desired outcome, the belief is spread to all members of the organization and becomes a reference point (phase 2). As the desired results continue to be achieved, the organization shifts its focus from the effects, which provides "evidence of the validity of its belief” (p. 122) to the cause, which remains prominent and becomes the ideal (phase 3). Finally the value, which is now believed by all in the organization, is taken for granted and begins to orient behavior (phase 4).

For example, if an owner of a new professional football team values experienced talent above all else, s/he will hire a GM and coaches who also value talent. The team will be built primarily through high-priced, established free agents. This initial team is successful for the first year, and proceeds to the first round of the playoffs, far exceeding expectations for any first year club in an established league. The value of building on talent spreads to others in the organization, and the team continues to build utilizing high priced free agents. Yet, salary cap restrictions, an aging roster, and a lack of chemistry eventually collude and leave the team at the bottom of the standings. Despite overwhelming evidence to the contrary, the team continues to recruit talented free-agents, as experienced talent has become an unquestioned ideological value despite current performance indications to the contrary. 
Fortunately, the situation outlined above is not irrevocable. Gagliardi (1986) also outlines three conditions for implementing culture change. First, there should be no antagonism between new values an organization is trying to promote and the old values an organization has held. Using the example above, it would be ineffective to say that talent no longer matters - only character and chemistry matter. That antagonizes an organization's ideology. Rather, it would be more effective to ingrain the value of instilling the new value that "we need to develop our own talent.” The second condition for culture change is that the organization needs to collectively experience success in exercising the new values. Accordingly, the organization that shifts values to developing talent from within needs to experience improvements when using that strategy. Finally, the leadership of an organization needs to promote a "mythical” interpretation of that success.

In an attempt to better understand these concepts, Smith (2003) conducted a survey study using 210 managers from different industries across North America. Roughly $28 \%$ of the respondents indicated that their organizations went through some type of culture change in the two years prior. Only 19\% of these attempted changes were rated as extremely successful. Ironically success was more likely when the sponsors (supporters of the change) were officers other than the CEO or COO. Successful change most strongly correlated with the following: the desired change was rewarded; the change effort was kept small; a dedicated project team was assigned; there was apparent support from a sponsor over the course of the project; and progress was tracked and publicized. Conversely, the key correlates to failed culture change include the departure of the 
sponsor $(r=-.58$; $p$.0005), key executives did not fully support the change $(r=-.39$; $p$ $<.0005)$, and that the culture did not support the change $(\mathrm{r}=-.37$; $\mathrm{p}<.0005)$.

Smith’s (2003) research paints a rather bleak picture of culture change, but also provides a salient guide to successfully implementing culture change. Kanter (2004) takes a more qualitative approach and examines change in "psychological" terms. Specifically, she examines prolonged success in business, sport, and even at the level of government to determine the qualities that bring about change. Kanter posits that confidence is the cornerstone of healthy organizations. There are three primary elements to confidence: accountability, collaboration, and initiative. The author defines accountability as an environment in which there is nothing to hide. Individuals want to share information, even negative information, because that could potentially strengthen the team. Individuals and groups constantly seek feedback and self improvement. Collaboration is defined as the desire to work with others. Initiative is defined as empowerment. Employees feel empowered and that their opinions matter. Kanter (2004) believes that winning streaks end when one of the three cornerstones erodes.

To go from a losing streak to a winning streak, Kanter believes that all major turnarounds have multiple commonalities. For one, leaders must make a decision about a situation that may have previously been ignored. In other words, all members of an organization must face the facts, admit responsibility for a problem, develop clear priorities and implement the means for clear performance feedback. "Ducking the facts about performance for fear of being judged, criticized, humiliated, and punished characterizes losing streaks, not winning streaks” (p.209). Secondly, it is necessary to increase collaboration. In a losing streak, individuals' confidence in one another is low. 
This must be restored, and this can be done through cultivating new ways to communicate, new topics of conversation, and jointly carrying out important work. Third, leaders must inspire initiative. This can be done through the empowerment of employees, and holding the honest belief in people and the ability to make a difference. It is important to note that culture change is not a goal in itself. It is a means to improve performance, to start “winning” again.

As mentioned earlier, Kanter believes that sport teams may represent simple examples of culture change. In her book Confidence: Leadership and the Psychology of Turnarounds, she outlines the transformation of the Philadelphia Eagles. This started with owner Jeffery Lurie, who purchased the Eagles for $\$ 185$ million. At the time of his purchase, the Eagles had a long history of losing. Lurie catalogued the key ingredients for a turnaround: a superb leader/coach; a franchise quarterback; an excellent player personnel department; an outstanding practice facility; and a new stadium. At first, Lurie hired Ray Rhodes, a disciplinarian. "Disciplinarian coaches, like tough corporate bosses brought into tighten things up, often wear out their welcome relatively quickly and players begin to just tune them out” (p.152). After Rhodes departed, Lurie hired Andy Reid, and the culture change continued. Together, Lurie and Reid formed a player's committee, built a new practice facility with no pillars for open environment, installed a cafeteria in central location, orchestrated film night for families of employees and players, and put tributes to Martin Luther King, Mother Teresa, and Jonas Salk in the lobby to signify the new values of the organization which went well beyond football. Over the past ten years, the Eagles have been one of the most successful organizations in the NFL. 
This story speaks to the importance within the field of sport psychology to have a working understanding of organizational culture, and the factors that influence whether a culture is assisting in the success of an organization or contributing to its decline. In working with leadership (owners, general managers) to systematically create a culture that is conducive to success, a sport psychology consultant can have a much greater impact than if s/he worked with a limited number of athletes on that team.

Kanter believes that leaders have a huge impact on the ability of their organizations to make changes, as they are the ones that have the greatest impact on culture. "The fundamental task of leaders is to develop confidence in advance of victory, in order to attract the investments that make the victory possible - money, talent, support, loyalty, attention, effort or people’s best thinking.” (p.19)

\section{Conclusion}

In an article by Chad Ford in ESPN.com evaluating the draft prospects of Yi Lang from China, Ford had this to say: “After seeing international players such as Yao Ming and Bargnani shine in a good situation and Darko Milicic suffer in a bad situation, they know that style of play, coaching, organizational culture and the opportunity to play will ultimately determine whether Yi fulfills his enormous potential” (Ford, 2007). This suggests that, along with some general mangers, even sportswriters understand how important organizational culture may be to the success of an athlete.

This review of literature has explained the constructs of climate and organizational culture, discussed the challenges in assessing organizational culture, outlined the role that leadership plays in developing and maintaining the culture, and linked the constructs of culture to performance in both business (empirically) and sport 
(analogously). Additionally, this paper has demonstrated the challenges of effectively changing culture once it is no longer conducive to successful performance. Most importantly, this review has highlighted the lack of research and information that exists about organizational culture in professional and collegiate sport. There is a wealth of information within business literature and, arguably, professional sport organizations are simply businesses with a very unique product: a team.

It would serve sport psychology consultants to examine sport organizations’ cultures in order to determine how an athlete's overall environment, not simply his or her thought processes about that environment, may impact performance. If culture has an impact on enjoyment, commitment, motivation, and performance within business, surely the sport psychology field could benefit in learning how to impact organizational culture in sport. In seeking this understanding, it makes sense to begin an initial exploration into organizational culture of professional athletics.

Specifically, leaders of professional sport organizations, filling both ownership and general management positions, are often seen as change agents. A new owner or general manager often has a dramatic impact on the on-field success of the teams that they oversee. Kanter (2004) clearly demonstrated how an owner had a significant impact on the success of a professional football team. Casual sport fans around the country have opinions on whether their team's owner/general manager is conducive to success, or rather act as a barrier to success. A contemporary example of this phenomenon is Isiah Thomas' disastrous tenure as general manager/coach of the New York Knicks basketball team. Thomas is widely criticized for handicapping that franchise, both financially and from a talent standpoint, for years to come (Ford, 2008). 
According to Schein (1990, 1992), this cultural exploration can be accomplished through qualitative methods. As mentioned earlier, owners and general managers are often credited for improving the fortunes of sport organizations. Through the interview of leaders who have successfully turned their respective franchises around, different elements of leadership and culture can be extracted that may have helped facilitate success. Questions regarding the change process, artifacts, values, and the underlying assumptions of an organization can be asked that might enlighten some of the processes and substance of successful culture change. For example, it would be beneficial to determine the values and underlying assumptions of the organization when it was struggling, how the new values and assumptions differ, and the type of process was implemented to bring about the transition. In clarifying the methods of successful sport executives, we can utilize their experience to take the first steps toward understanding, and eventually manipulating, organizational culture within sport organizations. 


\section{References}

Ames, C. (1992). Social motivation in youth sport. Journal of Sport \& Exercise Psychology, 25, 551-567.

Ashworth, B. (1985). Climate formations: Issues and extensions. Academy of Management Review, 10, 837-847.

Balthazard, P., Cooke, R., \& Potter, R. (2006). Dysfunctional culture, dysfunctional organization: capturing the behavioral norms that form organizational culture and drive performance. Journal of Managerial Psychology, 21(8), 709-732.

Bass, B. M. \& Avolio, B. J. (1997). Full range leadership development: Manual for the Multifactor Leadership Questionnaire. Palo Alto, CA: Mindgarden.

Colyer, (2000). Organizational culture in selected Australian sport organizations. Journal of Sport Management, 14, 321-341.

Cooke, R.A., \& Lafferty, J.C. (1989). Organizational culture inventory. Plymouth, MI: Human Synergistics.

Denison, D. (1996). What is the difference between organizational culture and organizational climate? A native's point of view on a decade of paradigm wars. Academy of Management Review, 21, 619-654.

Dutton, J., Dukerich, J. \& Harquail, C. (1994). Organizational images and member identification. Administrative Science Quarterly, 39(2), 235-263.

Falcione, R. \& Kaplan, E. (1984). Organizational climate, communication and culture. In R. M. Bostrom (Ed.) Communication Yearbook 8, pp. (285-309), Beverly Hills, California: Sage Books.

Ford, C. (2007). Can Yi play at the NBA Level? That's a good question. Retrieved online from ESPN.com on June 25, 2007. http://insider.espn.go.com/nba/draft2007/insider/columns/story?columnist=ford_chad \&page $=$ Yi-Conundrum\&lpos=spotlight\&lid=tab3pos2

Ford, C. (2008). Fixing the Knicks, Part 1: Isiah doesn’t make the grade. Retrieved online from ESPN.com on January 18, 2008.

http://insider.espn.go.com/nba/insider/columns/story?columnist=ford_chad\&page=K nicks-080118a

Gagliardi, P. (1986). The creation and change of organizational cultures: A conceptual framework. Organizational Studies, 7, 117-134.

Guba, E., \& Lincoln, Y. (1989). Fourth generation evaluation. Newbury Park, CA: Sage. 
Hays, K. (2006). Being fit: The ethics of practice diversification in performance psychology. Professional Psychology: Research and Practice, 37(3), 223-232.

Helfrich, L., Mohr, Meterko \& Sales (2007).

Kanter, R. (1983). The Change Masters: Innovation \& Entrepreneurship in the American corporation. New York: Simon \& Schuster.

Kanter, R. (2004). Confidence: Leadership and the Psychology of Turnarounds. New York: Random House Business Books.

Kent, R. (2001). Installing Change: an executive guide for implementing and maintaining organizational change, $2^{\text {nd }}$ Edition. Winnipeg, Pragma Press.

Kilman, R., Saxton, M. \& Serpa, R. (1985). Gaining Control of the Corporate culture, San Francisco, Jossey-Bass.

Kotter, J., \& Heskett, J. (1992). Corporate Culture and Performance. New York, The Free Press.

Kotter, J. (1990). A Force for Change: How Leadership Differs from Management. New York, The Free Press.

Lok, P. \& Crawford, J. (2003). The effect of organizational culture and leadership style on job satisfaction and organizational commitment: a cross-national comparison. Journal of Management Development, 23, 321-338.

Lee, S., Wagstaff, C., Fletcher, D., \& Hanton, S. (2007). The psychosocial dynamics of organizational effectiveness: Common themes throughout the mainstream and sport literatures. Journal of Sport and Exercise Psychology, 29, 180.

Lencioni, P. (2002). The Five Dysfunctions of Team. San Francisco, CA, Jossey-Bass.

Louis, M. (1985). An investigator's guide to workplace culture. In P. Frost. L. Moore, M. Louis, C. Lundberg, \& J. Martin (Eds.), Organizational culture (pp. 73-94). Beverly Hills, CA: Sage.

Martin, J. (1992). Cultures in Organizations: Three Perspectives. New York, Oxford University Press.

Martin, J. (2002). Organizational Culture: Mapping the Terrain. Thousand Oaks, CA, Sage Publications. 
McMurray, A. (2005). The relationship between organizational climate and organizational culture. Journal of American Academy of Business, 3 1-8.

Merriam, S. \& Associates, (2002). Qualitative Research in Practice: Examples for Discussion and Analysis. San Francisco, CA, Jossey-Bass.

Meyers, A., Coleman, J., Whelan, J. \& Mehlenbeck, R. (2001). Examining careers in sport psychology: who is working and who is making money? Professional Psychology: Research and Practice, 32(1), 5-11.

Meyerson, D., \& Martin, J. (1987). Cultural change: an integration of three different views. Journal of Management Studies, 24, 623-647.

Mills, A. (1988). Organization, gender, and culture. Organizational Studies, 9, 351-370.

O’Reilly, C., Chatman, J., \& Caldwell, D. (1991). People and organizational culture: a profile comparison approach to assessing person-organization fit. Academy of Management Journal, 34(3), 487-516.

Patton, M. (2002). Qualitative Research and Evaluation Methods, $3^{\text {rd }}$ Edition. Thousand Oaks, CA, Sage Publications.

Phelan, M. (2005). Cultural revitalization movements in organization change management. Journal of Change Management, 5(1), 47-56.

Quinn, R. E. \& Spreitzer, G. M. (1991). The psychometrics of the competing values culture instrument and an analysis of the impact of organizational culture on the quality of life. Research in Organizational Change and Development, 5, 115-142.

Sarros, J., Gray, J. \& Densten, I. (2002). Leadership and its impact on organizational culture. International Journal of Business Studies, 10(2) 1-26.

Schein, E. (1983). The role of the founder in creating organizational culture. Organizational Dynamics, $X$, 13-28.

Schein, E. (1985). Organizational Culture and Leadership. San Francisco. Jossey-Bass.

Schein, E. (1990). Organizational culture. American Psychologist, 45(2), 109-119.

Schein, E. (1992). Organizational Culture and Leadership, $2^{\text {nd }}$ Edition. San Francisco. Jossey-Bass.

Sheridan, J. (1992). Organizational turnover and employee retention. Academy of Management Journal, 35 (5), 1036-1056. 
Singh, J. (2006). The rise and decline of organizations: can entrepreneurs' play a saviour’s role? Vikalpa: The Journal for Decision Makers, 31(1), 123-127.

Smerek, R. \& Denison, D. (2007). Social capital in organizations: Understanding the link to firm performance. Academy of Management Proceedings, 2007, 1-6.

Smith, M. (2003). Changing an organisations's culture: correlates of success and failure. Leadership and Organizational Development Journal, 24, 249-261.

Smith, R. \& Smoll, F. (1997). Coach-mediated team building in youth sports. Journal of Applied Sport Psychology, 9, 114-132.

Wallach, E. (1983). Individuals and organizations: the culture match. Training and Development Journal, 2, 29-36.

Williams, J., \& Straub, W. (2001). Sport Psychology: Past, Present, Future. In J.Williams (Ed.) Applied Sport Psychology: Personal Growth to Peak Performance, $4^{\text {th }} \mathrm{ed}$. (pp.1-12).Mountain View, CA: Mayfield Publishing Co.

Zaichkowsky, L. \& Naylor, A. (2005). Sport psychology foundations, organizations, and related resources. Journal of Applied School Psychology, 21(2), 9-24. 